\title{
Measurements of structures and concentrations of carbon particle species in premixed flames by the use of in-situ wide angle $X$-ray scattering
}

Frederik Ossler ${ }^{1 *}$, Sophie E. Canton ${ }^{2 a, 2 b}$, L. Reine Wallenberg ${ }^{3}$, Anders Engdahl ${ }^{4}$, Soenke Seifert ${ }^{5}$, Jan P. Hessler ${ }^{6}$, and Robert S. Tranter ${ }^{6}$

${ }^{1}$ Combustion Physics, Lund University, P.O. Box 118, SE 221 00, LUND, Sweden

${ }^{2 a}$ IFG Structural Dynamics of (Bio)chemical Systems, Max Planck Institute for Biophysical Chemistry, Am Fassberg 11, D-37077 Goettingen, Germany.

${ }^{2 b}$ FS-SCS, Structural Dynamics with Ultra-short Pulsed X-rays, Deutsches

Elektronensynchrotron DESY, Notkestrasse 85, D-22607 Hamburg, Germany

${ }^{3}$ Polymer and Materials Chemistry, and Centre for Analysis and Synthesis, P.O. Box 124, SE 221

O0, Lund University, LUND, Sweden

${ }^{4}$ MAX IV Laboratory, Lund University, P.O. Box 118, SE 221 00, LUND, Sweden

${ }^{5}$ X-ray Science Division, Argonne National Laboratory

9700 South Cass Avenue, Argonne IL 60439, USA

${ }^{6}$ Chemical Sciences and Engineering Division, Argonne National Laboratory

9700 South Cass Avenue, Argonne IL 60439, USA 
150916 Time 16:20

Revised September 16, 2015

e-mail list of authors:

Frederik Ossler: ${ }^{*} \quad$ frederik.ossler@forbrf.lth.se

Sophie E. Canton: $\quad$ sophie.canton@desy.de

L. Reine Wallenberg: reine.wallenberg@chem.lu.se

Anders Engdahl: $\quad$ anders.engdahl@maxlab.lu.se

Soenke Seifert: $\quad$ seifert@anl.gov

Jan P. Hessler: $\quad$ janp137@comcast.net

Robert S. Tranter: $\quad$ tranter@anl.gov

"Corresponding Author: frederik.ossler@forbrf.lth.se, Tel. +46-46-2224832, Fax +46-462224542 


\begin{abstract}
In-situ wide-angle X-ray scattering (WAXS) measurements have been conducted on atmospheric-pressure fuel-rich premixed freely propagating ethylene/oxygen flames with argon and nitrogen dilution. In this work, a novel analysis methodology able to provide quantitative information on soot/carbon particle species and concentrations was tested under heavy sooting conditions. The particle composition and concentrations were retrieved by fitting theoretical calculations of structural components from major molecular and nanometric species to the experimental WAXS data. The results show that argon dilution yields predominantly graphenelike components that are less stacked and amorphous carbon that is less structured than under nitrogen dilution. This finding was later confirmed by electron microscopy analysis on samples extracted from similar flames. In addition, the WAXS showed that most of the carbon present in the flames was bound as particles. These results constitute some of the first in-situ observations on structures and concentrations of carbon species in laboratory burner flames operating without stabilization plates.
\end{abstract}

Key Words: In-situ measurements, Soot, Nanoparticles, Structure, Concentrations, WideAngle X-ray Scattering, Flame. 


\section{Introduction}

Soot and nanoparticles from combustion are of considerable interest as commercial products and because of the impacts they can have on health [1-3] and the environment [4-8]. During the last decade much attention has been directed towards unraveling the mechanisms that control particle production $[9,10]$. They span wide ranges of length and timescales [10-13], and molecular dynamics simulations show that carbon cluster formation and structural changes are strongly dependent on temperature [14-17]. To significantly advance models of particle generation and destruction, it is necessary to develop complementary theoretical and experimental tools that probe reactive structures on the atomic scale, and provide accurate size distributions. Many experimental techniques that are routinely employed to study particle formation [18-41] require physically extracting the samples from the reaction/flame region. This usually introduces local disturbances on the temperature and flow conditions, hence on the formation dynamics and concentrations. Consequently, non-perturbative in-situ measurements are preferable. Hard X-ray methods utilizing photons of wavelengths comparable to interatomic distances have considerable potential for interrogating morphology and chemical bonding. These techniques can overcome some of the limitations of laser techniques [42,43] that operate in the infrared to ultraviolet regions and frequently suffer from interference by flame/reactor background radiation. In addition, the intensity and resolution of optical signals generally decrease with increasing size, temperature, and internal energy of the soot precursor molecules such as polycyclic aromatic hydrocarbons (PAHs) [42-46].

Three principle X-ray techniques have been applied to soot formation studies: X-ray absorption spectroscopy (XAS); small-angle X-ray scattering (SAXS); and wide-angle X-ray scattering 
(WAXS). XAS methods are most suitable for ex-situ studies, since they are element sensitive and can probe the local environment around the absorbing atom and thus deliver important chemical information on solid carbon [47]. For carbon species absorption occurs in the soft X-ray wavelength region and therefore requires relatively low pressure conditions. WAXS is primarily sensitive to two parameters: the size of the electron cloud of a free atom (such as that of argon) and the distance between atoms in a molecule. The technique is usually applied in the hard X-ray wavelength region technique and therefore can be employed for in-situ atmospheric- and highpressure in-situ measurements to 'sense' the structure of small nanoparticles and soot $[48,49]$. Among the three, SAXS is probably the most extensively used technique for in-situ studies of the size distributions and morphologies of nanoparticles and soot [50-56]. The X-ray techniques have also been combined to give a more complete picture on the properties of soot. XAS methods have been used by Braun et al. [57] in combination with ex-situ WAXS to obtain the size of graphitic crystallites, lattice spacing and relative proportions of aliphatic and aromatic species in soots. This detailed structural information was complemented by SAXS measurements that determined sizes and fractal dimensions of particles. SAXS and WAXS have also been applied in-situ in flames, supplying important information on the sizes, fractal properties, concentrations, and structure of soot and nanoparticles that has given more insight into the formation dynamics of soot and precursors [58-60].

Among the above mentioned techniques WAXS has a particular advantage in that it can provide information on the clustering and atomic level arrangement of atoms and thus deliver important information of the chemical character of carbon containing molecules, clusters and particles. Insitu studies on nanoparticles and soot were performed by Ossler and co-workers [58-60] on flames stabilized with a plate that created a high density of particles just below the plate surface 
that could be probed with a relatively low flux X-ray source $\left(\sim 10^{10}\right.$ photons/s $)$ [49]. While valuable information is obtained from such measurements the presence of the plate perturbs the flow field in the flame. SAXS usually yields higher signals than WAXS and has been applied to flames without plates that are stabilized just by the burner surface [50-56]. In this manuscript these flames will be referred to as freely propagating flames and are preferred as the flow fields are not perturbed. However, the particle densities are much lower than just beneath a stabilization plate and much higher photon fluxes are required for adequate in-situ WAXS measurements.

In this work we present a novel methodology with results from an exploratory study on the use of intense X-ray radiation to obtain in-situ quantitative structural/chemical information and concentrations about carbon-based nanoparticles that were produced in fuel rich freely propagating atmospheric pressure flames. The work describes how particle species concentrations and structural information were obtained from the WAXS profiles and chemical calculations. From these data the amount of carbon bound in small molecular species and particles was also determined.

\section{Scattering cross sections}

\subsection{Definitions}

The theoretical background on coherent and incoherent scattering required for interpreting the experimental data presented in this work has been described in detail in [49] and references therein. Thus only a brief overview of the essential equations is outlined below. Additional details and sources to atomic scattering data can be found in [61] and references therein. For the hydrogen atom the cross sections given by Bentley and Stewart were used. Whereas, the floated sphere approach by Stewart et al. was used for the cases of hydrogen molecules and hydrogen 
bonded to other atoms, (see [61], p 536, and references therein). The free atom approximation [61], which is used for the other atoms (carbon, oxygen nitrogen and argon) in our calculations appear also to work well for hydrogen atoms for the level of approximation in this work.

The observed scattering intensity is given by equations (1-3).

$I(q(\lambda, \theta), \theta, \varphi)=I_{0} c r_{e}^{2} p(\theta, \varphi) N \sum_{j=1}^{m} x_{j}\left[\frac{d \sigma(q)}{d \Omega}\right]_{j} \Delta \Omega(\theta) \Delta V(\theta)$

$q=(4 \pi / \lambda) \sin (\theta / 2)$

where $q$ is the exchanged momentum, $\lambda$ is the wavelength of the X-rays, and $\theta$ is the scattering angle.

$p(\theta, \varphi)=\sin ^{2} \varphi+\cos ^{2} \varphi \cdot \cos ^{2} \theta$

alternatively

$p(\theta, \varphi)=1-\cos ^{2} \varphi \cdot \sin ^{2} \theta$

The measured intensity, I, depends on the number of photons per second collected by the detection system, $c$ is the calibration constant, $r_{e}$ is the classical electron radius, $I_{0}$ is the intensity of the X-ray beam expressed as the number of photons per second, $N$ the total concentration of species, $x_{j}$ the relative concentration or mole fractions of species $j$. These can also be expressed in terms of parts per million, $\mathrm{ppm}_{j}=1 \times 10^{6} x_{j} .(d \sigma / d \Omega)_{j}$ is the differential cross section of species $j$ and it is given in electronic units (e.u.). $\Delta \Omega$ and $\Delta V$ are the solid angle and the volume of detection, respectively, and are functions of $\theta$. The factor $p(\theta, \varphi)$ contains the dependence on the inclination of the scattering plane relative to the direction of the plane of polarization of the X-ray radiation. 
In order to simplify the analysis one can calculate the total normalized cross section, $\tau(\mathrm{q})$, defined by Eq.(4a), as part of Eq. (1). The normalization is given by Eq. (4b).

$$
\begin{aligned}
& \tau(q)=\sum_{j=1}^{m} x_{j}\left[\frac{d \sigma(q)}{d \Omega}\right]_{j} \\
& \sum_{j=1}^{m} x_{j}=1
\end{aligned}
$$

While equation (1) should allow extracting the absolute scattering intensity, the actual values are particularly sensitive to the accuracy of $c, \Delta V$, and $\Delta \Omega$. In order to minimize the effect of fluctuations in these parameters, it is very convenient to cast the experimental data as ratios of scattering signals to a reference signal $[58,60]$. In this work the scattering signal from the flame is divided by that from a cold flow reference to yield the ratio, $\gamma$, Eq.(5a).

$$
\begin{aligned}
& \gamma(q)=\frac{I_{f}(q, \theta, \varphi)}{I_{c}(q, \theta, \varphi)}=\frac{N_{f}}{N_{c}} \frac{\tau_{f}(q)}{\tau_{c}(q)} \\
& \gamma(q)=\frac{T_{c}}{T_{f}}\left\{\sum_{j=1}^{m} x_{f, j}\left[\frac{d \sigma(q)}{d \Omega}\right]_{j}\right\} /\left\{\sum_{j=1}^{m} x_{c, j}\left[\frac{d \sigma(q)}{d \Omega}\right]_{j}\right\}
\end{aligned}
$$

$N_{f}$ and $N_{c}$ are the total number concentrations of the flame and the cold flows, respectively. Assuming constant pressure and the perfect gas law, $p V=n R T$, one gets Eq.(4b) from $\frac{N_{f}}{N_{c}}=\frac{T_{c}}{T_{f}}$ and Eq.(5a).

\subsection{Specific species cross sections}

Within a flame there may be several hundred or more individual species that contribute to the observed WAXS signal. It is impractical to calculate scattering cross sections for each species and generic cross sections for groups or classes of species are adequate for all but the most 
abundant species. Based on Eq. (1) we therefore treat the scattering from the flame as the contribution from the three different groups, which are defined with respect to their size or number of carbon atoms: (1) Atoms and small molecular (major concentration) species with two carbon atoms; (2) particle precursors or polycyclic aromatic hydrocarbons (PAHs) with up to 100 carbon atoms; and (3) small structural species representing either small nanoparticles or components of larger particles with more than 100 carbon atoms as will be explained in the following sections. Their respective number concentrations are given as $N_{f}, N_{g}$, and $N_{p}$, where the suffices $f, g$, and $p$ stand for "flame", "precursor/PAH/graphene", and "particle.

In order to obtain the total theoretical $\chi(q)$ to be compared with the experimental measurements the scattering from the major concentration molecular species of group (1) in the flame at the measurement $\mathrm{HAB}$ have to be added to that from the precursors and particles of groups (2) and (3). The molecular species concentrations were estimated from chemical kinetic simulations of the flames which are discussed in section 4.2. To obtain the best fit between the experimental profiles and the calculated ones the balance between molecules, particles and precursors have to be adjusted. The sensitivity to the level of detail in these simulations is examined later.

In the following sections the effect different species in the three size groups have on the structure of the angular pattern of $\chi(q)$ is shown by plotting their $d \sigma / d \Omega$ against $q$. In order to simplify the analysis a set of structural groups were selected that may not necessarily represent a pure single substance (e.g. precursor, particle etc.), but should be interpreted as structural components that relate to specific features of the scattering signal and that could represent either free small nanoparticles or parts of larger particles. Information on the size and morphology of particles has 
to be gained from complementary experiments such as SAXS. The size of these species was limited to approximately 2 nanometers and up to 352 carbon atoms. The aromatic or PAH components were defined as containing 88 carbon atoms so that 4 layers yield a 352 atom graphite unit. This simplification gives a direct way to test how structural changes affect the scattering while maintaining a constant number of carbon atoms. The effect of changing the number of carbon atoms within the same structural system has also been examined and principally changes the amplitude of the scattering cross section, but does not affect the main properties of the shape of the profile. Some crystallographic effects such as the width or sharpness of a feature corresponding to a lattice plane do change with the number of carbon atoms, but they were of minor importance in our study and were only considered on a qualitative basis, partially because of the limited angular resolution of the detector.

\subsubsection{Atomic and molecular major concentration species:}

As shown in Fig. 1 the $d \sigma / d \Omega$ for air and of the major atomic and molecular species, Ar, $\mathrm{N}_{2}$, $\mathrm{CO}, \mathrm{O}_{2}, \mathrm{H}_{2}, \mathrm{CH}_{4}, \mathrm{H}_{2} \mathrm{O}, \mathrm{C}_{2} \mathrm{H}_{2}, \mathrm{C}_{2} \mathrm{H}_{4}, \mathrm{H}_{2} \mathrm{CO}$, and $\mathrm{CO}_{2}$ show intensities that decrease and display slow changes of the slope with increasing $q$. Thus from a signal analysis point of view only low frequency components (in terms of the q-pattern) appear for the small molecules and that the frequency increases with the size of the molecules or particle. All the reported atomic and molecular species show cross sections which present a monotonic dependence on $q$, where they decrease to at least $q=4 \AA^{-1}$. The largest molecules, $\mathrm{C}_{2} \mathrm{H}_{4}, \mathrm{C}_{2} \mathrm{H}_{2}$, and $\mathrm{CO}_{2}$, show a small local maximum for $5 \AA^{-1}<q<6 \AA^{-1}$.

\subsubsection{Particle precursors and PAH/graphene:}

Within a flame there may be many aromatic species ranging in size from benzene to tens of carbon atoms that could be considered as precursors to primary soot particles. In this work 
particle precursors are defined as species that contain up to circa 100 carbon atoms. The $d \sigma /$ $d \Omega$ of several aromatic species and $\mathrm{C}_{60}$ are shown in Fig.2. The aromatic species include benzene, naphthalene, and perylene to represent the smaller aromatics or polycyclic aromatic hydrocarbons (PAH). Larger PAHs were represented by nanometer sized graphene with 88 carbon atoms. In actual PAH there are $\mathrm{H}$-atoms bound to the edge carbon atoms. However, these were not included in the calculation of $d \sigma / d \Omega$ which introduces $<5 \%$ error to the scattering profile for a large PAH.

\subsubsection{Particle species:}

In the following sections we show that nanoparticles or nanosized structural components generally have significant features related to their overall size and shape or morphology that appear in regions of the WAXS signals that differ from the features generated by atoms or molecules. Nanometer sized units or structural elements tend to appear with higher frequency components and can be separated from the scattering contribution of the flame gases in group (1). As a first approach two groups were selected to describe the structural properties of the small nanometer sized constituents: (i) Highly structured graphitic units of either type AA (Fig. 3a-c) or AB (Fig. 4a-c), where AA corresponded to parallel stacking of 88 carbon atom graphene sheets (Section 2.2.2), and $\mathrm{AB}$ to alternating shifts between layers of $1.42 \AA$ in the "armchair" direction; (ii) Amorphous elements (Fig. 5a-c) containing low levels of structure.

The calculated differential cross sections for the graphitic species were dependent upon the number of graphene-like layers and the interlayer separation. Figs. $3 b$ and $4 b$ show the effect of number of layers on the scattering. In Figs $3 c$ and $4 c$ the number of layers is fixed at 6 but the inter-layer spacing is varied from $3.3 \AA$ to $3.7 \AA$ in steps of $0.1 \AA$. Differences in the heights and 
locations of peaks in the calculated $d \sigma / d \Omega$ occur as the structure is stretched or compressed. Prior studies on bi-layered graphene (see [62] and references therein) indicate that the binding energy of $\mathrm{AA}$ should be lower than that of $\mathrm{AB}$ and the equilibrium distance between adjacent layers should also be slightly larger.

The amorphous species were represented by chains having specific carbon-carbon (C-C) distances. The various amorphous structures were obtained from a random generator that constrained bond angles to ensure that the closest distance between two carbon atoms would not be less than the chosen $\mathrm{C}-\mathrm{C}$ bond length. Some representative structures, e.g.Ch_1 (Fig. 5a), were created with bonds lengths of $1.42 \AA$ that are similar to aromatic bonds. Additionally, structures with aliphatic bonds lengths of $1.54 \AA$ A, e.g. Ch_2 (Fig. 5b), were created. Different types of chains within each of these two bond length groups were selected based on the properties of the profiles of their differential scattering cross sections. The structures were randomly generated chains containing 350-352 carbon atoms. Fig 5c displays $d \sigma / d \Omega$ for structures Ch_1 and Ch_2, which are just two of the many structures created by the random generator. Ensemble average scattering cross-sections, Fig. 5c, have been calculated from the specific scattering cross sections for each structure created by the random generator. These averages are referred to as Av_1 and Av_2, corresponding to the respective bond lengths 1.42 and $1.54 \AA$. The calculations show that for $q<2.5 \AA^{-1}$ the scattering is mainly sensitive to the resulting large scale chain structure or the way the atoms cluster at each run and is dependent on the specific morphology, e.g., the elongation and contraction of the chain, as well as the internal grouping of atoms. For instance in the large scale structure the two strands/lobes, in Fig. 5a are responsible for lowering the intensity in the scattering profile in the region $1.5 \AA^{-1}<q<2.0 \AA^{-1}$ of Fig. 5c, close to the same region 
where graphitic stacking produces a peak, see Figs. 3b,c and Figs. 4b,c. This is in agreement with the findings in [49] that the shape of clusters affects the scattering profile for $q<2.5 \AA^{-1}$. Fig.5c also shows that for $\mathrm{q}>2.5 \AA^{-1}$ the scattering is mainly sensitive to the choice of the bond length. Another result of the calculations (see Fig. 6) is that in this $q$ region the scattering is well represented by that produced by a statistical ensemble of specific bond lengths and not that by that from a single (average) bond representation. Consequently, significant chemical information on structural species can be derived from scattering measurements on ensembles.

The specified number (350-352) of carbon atoms was used for many of the calculations because they would produce the same carbon mass as that of graphitic species described previously. The number of carbons atoms for both the graphitic and amorphous structures appeared as a reasonable choice with respect to the width of the signatures observed from the scattering measurements described in the experimental section. For the graphitic structural components AA and $\mathrm{AB}$ with 352 atoms, i.e., four sheets of the graphene units separated by $3.4 \AA$ were the primary choices for the fits.

\section{Experimental}

The experiments were conducted at the BESSRC beam line 12-ID-C of the Advanced Photon Source (APS) at Argonne National Laboratory. The energy of the X-ray beam was $12.0 \mathrm{keV}$ $(1.03 \AA)$. The spectral bandwidth was $2 \%$ or better, and the incident average power was $\sim 1 \mathrm{~W}$ in a rectangular cross-section of $600 \mu \mathrm{m}$ x $600 \mu \mathrm{m}$ (Flux $\sim 10^{16}$ photons $\mathrm{s}^{-1}$ ). A premixed atmospheric pressure ethylene/oxygen flame diluted with either $\mathrm{Ar}$ or $\mathrm{N}_{2}$ was generated above the surface of a porous bronze-plug, McKenna-type, burner [63]. The inner diameter of the premixed 
region was 0.75 inches $(1.9 \mathrm{~cm})$ and the outer diameter of the co-flow region was 1.25 inches $(3.2$ $\mathrm{cm})$. The flame was shielded from the ambient air by a co-flow of nitrogen.

The experiments were performed with the flow conditions given in Table 1. The burner was operated at a fuel rich condition with carbon/oxygen ratios $(\mathrm{C} / \mathrm{O})$ between 0.76 and 0.95 , corresponding to equivalence ratios $(\Phi)$ between 2.3 and 2.8. This enabled producing high soot concentrations at relatively low heights above the burner surface (HABs) where the burning conditions were most stable. Typically this occurred close to $\mathrm{HAB}=10 \mathrm{~mm}$ where most of the measurements were performed. The flows had to be kept relatively constant to sustain stable burning conditions. Consequently, only one input flow parameter was slightly changed at a time giving systematic changes between flames with the same diluent. Unfortunately, this also resulted in small changes to the overall flow velocity between flames making quantitative comparisons more difficult. The effect of the flow changes on the major molecular species composition and flame temperature were estimated by chemical kinetic calculations described in the following sections. The flame temperatures could not be measured by thermocouple during the WAXS experiments due to spatial constraints and the difficulty of making sufficiently accurate measurements in a sooting flame. However, it is possible to extract estimates for the flame temperatures from the WAXS data that could be compared to offline measurements as discussed in section 4.2.

The Ar flames were shorter and wider for similar flow settings than those with $\mathrm{N}_{2}$, which is consistent with the higher temperatures and reaction rates in the argon-diluted flames. In order to stretch the Ar flames to dimensions comparable to the $\mathrm{N}_{2}$ ones the flow rates of the fuel and 
argon had to be increased. This eventually also caused the flame to lift from the burner limiting the useable range of flow rates. In addition to flame measurements, two measurements were made with the flame extinguished and the fuel turned off. These cold flow measurements provided reference signals for analyzing the flame measurements, section 2.1, and will be referred to as Aref and Nref for argon and nitrogen flows respectively.

The WAXS measurements were performed with a rotating-detector arrangement, described previously [49] and shown in Fig.7. It consists of a scintillator/photomultiplier tube ( $\mathrm{ZnS}: \mathrm{Ag}$ / Hamamatsu H6780) mounted on a computer controlled rotation stage. The angle between the scattering- and beam-polarization planes was $\varphi=50^{\circ}$. The output of the photomultiplier was connected to a low-noise trans-impedance preamplifier followed by a voltage-to-frequency converter. The resulting frequency was measured with a scaler. The integration time at each angle was 5.0 seconds. The rotating detector was scanned over the range of scattering angles, $\theta$, from $14^{\circ}$ to $95^{\circ}$, in steps of $1^{\circ}$. The resolution of the detection system was $0.6^{\circ}$. The range of the detector extended from $1.38<q<10.50 \AA^{-1}$. The power of the incident beam was monitored with a helium filled ionization chamber, a low-noise trans-impedance preamplifier, and a voltage-tofrequency converter followed by a second scaler.

Because the intersection between the line of sight of the detector and the crossing X-ray beam (i.e., the depth of view,) was proportional to $1 / \sin (\theta)$, the scattering around $\theta=90^{\circ}$ yielded particularly high spatial resolution but was very sensitive to any misalignment between the vertical center-line of the flame and the center of rotation of the detector. Moreover any inhomogeneity and fluctuations inside the flame close to the high-temperature core region can 
easily affect the scattering signal, as discussed in section 4.1. Consequently, this paper focuses on the average properties of the flames for scattering angles between $15^{\circ}$ and $65^{\circ}\left(1.5 \AA^{-1}<q<6.5\right.$ $\AA^{-1}$ ) which are less susceptible to these effects.

\subsection{Retrieval of particle data by a fitting procedure}

The following iterative fitting procedure was used to retrieve the species composition and temperature from the experimental $\gamma(q)$ based on the outline given in section 2.1.

1) The cold-flow reference scattering was calculated for the flow conditions in Table 1;

2) Scattering from the major molecular and atomic species in the flames (section 2.2.1) was estimated from concentrations obtained from chemical kinetics calculations.

3) Scattering from precursors in section 2.2.2 and graphitic species for the structures AA and $\mathrm{AB}$ described in section 2.2.3 were added to the flame gas scattering from step (2);

4) Scattering from amorphous species based on the structures in Figs. 5a and 5b which are described in section 2.2.3 was added to the scattering obtained at step (3);

5) The resulting total flame composition scattering from step (4) was divided by that of the reference mixture from step (1);

6) The nanoparticle composition, e.g., combination of amounts of precursor/graphene, AA, AB, chains Ch_1 (C-C $1.42 \AA)$ and Ch_2 (C-C $1.54 \AA$ ), or statistical average representations of the chains $A v \_1$ and $A v \_2$ were adjusted to improve the curve shape of the calculated $\gamma(q)$ with respect to the experimentally measured one;

7) The theoretical curve was scaled by adjusting the flame temperature to obtain the best agreement between theoretical and experimental data and thus the ratio between room temperature $\left(T_{c}=298 \mathrm{~K}\right)$ and estimated flame temperature $\left(T_{f}\right)$ given by Eq. $(5 \mathrm{~b})$; 
8) Points (6) and (7) were iterated until the best fit was obtained to minimize the root-mean square difference sum (RMSD) given in Eq. (6).

$R M S D=\sqrt{\sum_{i=1}^{n}\left(\gamma_{c a}\left(q_{i}\right)-\gamma_{e x}\left(q_{i}\right)\right)^{2} / n}$

$\gamma_{c a}\left(q_{i}\right)$ and $\gamma_{e x}\left(q_{i}\right)$ are the calculated and experimental values, respectively.

As the fitting procedure was developed it became clear that two parameters had the largest effect on the simulated signals. These were the contributions from nanometer sized carbonaceous structural components of particles and the temperature.

\section{Experimental results and discussion}

Scattering data were obtained for six flames and two cold reference flows. Figs. $8 \mathrm{a}$ and $8 \mathrm{~b}$ present scattering data related to the Ar-diluted, Al-A3, flames and the reference measurement, Aref. Similar data are displayed in Figs. $8 \mathrm{c}$ and $8 \mathrm{~d}$ for the $\mathrm{N}_{2}$-diluted, N1-N3, flames and Nref, the nitrogen reference flow. In Figs. 8a and 8c the scattering intensities normalized by the intensity of the X-ray beam are given. The drop in intensity with decreasing $q$ for $q<1.7 \AA^{-1}$ is attributed to the partial shielding caused by the geometry of the beam line. Both the flame and the reference measurements show the same decrease which thus cancels out in the ratios of scattering intensities obtained from equation 4a. These ratios are shown in Figs. 8b and 8d. For comparison, a scattering profile normalized against the nitrogen-dilute reference signal is displayed for a carbon soot sample ${ }^{*}$ in Fig.8 (e). The most obvious features of Figs.8 (b) and (d), are the peaks at values of $q$ between 1.7 and $1.9 \AA^{-1}$. They are strikingly similar to those given by the carbon soot reference, indicating that graphitic structures are present in the flames.

\footnotetext{
* A sample of soot was deposited on a metal substrate by passing it through a sooting ethylene flame. After the flame had been turned off the sample was inserted into the measurement volume and the WAXS profile acquired.
} 


\subsection{Homogeneity of the measurement volume}

A potential complication in interpreting the experimental signals is that inhomogeneities (mentioned in section 3) in the reaction volume can strongly influence the scattering signal particularly close to $\theta=90^{\circ}$. These can arise, in part, from fluctuations in the flame causing local variations in density and temperature that result in changes in species concentrations. The flames in the current work were created from premixed gases and are, in principle, axisymmetric. Thus the spatial variations of density, temperature and species composition should be simply a function of $\mathrm{HAB}$ and independent of the radial position. However, in an angular region around $\theta=90^{\circ}$ the experimental and calculated scattering signals deviate (see Fig. 9). This region corresponds to that of the highest spatial resolution and therefore the measurements are very sensitive to local variations in density, which may arise from many sources including non-ideal flows or local heating by radiating soot particles. These processes and their effects on flames are very challenging to model accurately and may lead to limitations in the range of scattering angles from flames that can be reliably studied with WAXS. For this exploratory study all the theoretical calculations of the gas and particle compositions were based on homogeneous systems and did not account for radial variations.

Comparisons of calculated and experimental data are shown for the $A l$ and $N 1$ flames in Fig. 10. Large deviations between the calculations and experiments were found in the scattering regions $75^{\circ}<\theta<110^{\circ}$ corresponding approximately to $6.5 \AA^{-1}<q<10.5 \AA^{-1}$, particularly for the $N 1$ flame. For the other flames $(A 2, A 3, N 2$, and $N 3)$ similar deviations were found over a wider range, $5.2 \AA^{-1}<q<10.5 \AA^{-1}$. Despite these deviations in $\chi(q)$ there are fine features within these regions that match between experiments and calculations. From the analysis of the deviations they are most likely due to the position of the rotation center of the detection system being 
slightly off-axis and upstream of the X-ray beam as given in Fig.9, rather than variations in flame properties. This is supported by the observation that there was considerable symmetry in the deviations between measurements and calculations around $\theta=95^{\circ}$. The deviations also appear to depend on $\mathrm{HAB}$. For the flames measured at $\mathrm{HAB}=10 \mathrm{~mm}(N 1-N 3, A 2, A 3)$ a small region $(1.5-$ $2.0 \mathrm{~mm}$ in diameter) at the center showed lower density than the rest of the flame. This could be an effect of higher temperature at the center and/or lower concentration of soot particles. For the Al flame, which was measured at $\mathrm{HAB}=8 \mathrm{~mm}$ the center region presents more of a doughnutlike density or temperature structure.

\subsection{Estimation of flame temperature and composition}

In the course of this work the sensitivity of the WAXS profiles to flame temperature has become apparent. In an improved experimental setup the flame temperature would ideally be measured simultaneously with the WAXS signal. However, this is impractical particularly for sooting atmospheric pressure flames; in part due to space constraints and in part due to the opacity of the flame. Thermocouple measurements have been reported for sooty flames [37], but obtaining uncertainties of $\pm 50 \mathrm{~K}$ is difficult even with the well-described methods of Shaddix and coworkers [38]. Uncertainties of $\pm 100 \mathrm{~K}$ are more typical in sooting flames and the small diameter burner used in this work makes accurate thermocouple measurements more challenging. Following the WAXS experiments we tested thermocouple measurements on similar flames generated with a different, but similar, burner in a laboratory. As anticipated, the results showed significant variability for a number of reasons including: the relatively small volumes of the flames; effect of the probe on the local flame environment; rapid deposition of soot on the thermocouple in the $\mathrm{N}_{2}$ diluted flame. As an alternative the temperature difference between the Ar and $\mathrm{N}_{2}$ diluted flames $A 1^{\prime}$ and $N 1^{\prime}$, that were analogous to $A l$ and $N 1$ was estimated based on 
the ratio of the spontaneous radiative emission (up to $1000 \mathrm{~nm}$ ) measured from the sooty region by a small fiber coupled spectrometer. This radiation was compared with the corresponding ratio resulting from the theory of Planck blackbody radiation. The results indicated that the argon diluted flames were about $100 \mathrm{~K}$ hotter than the nitrogen diluted ones. There is little doubt that flame temperature is a key parameter in interpreting WAXS data quantitatively and developing a method that allows it to be obtained simultaneously with the WAXS signal will be an important improvement. Due to the challenges of obtaining accurate flame temperature measurements the temperature at the $\mathrm{HAB}$ at which the WAXS signal was collected was treated as a fitting parameter and obtained from Eq. (5b), section 2.1. The fitting was done without any a priori knowledge of temperature. The only influence of the temperature in the fitting procedure was from the major species concentrations that were normalized (i.e., the resulting sum was set to 1). The experimental investigations were made at HABs where much of the fuel has been converted to particles and particle precursors. Consequently, the contribution of small gas phase species to the observed scattering profile is only weakly dependent on the HAB. For measurements at lower $\mathrm{HAB}$ and particularly close to the flame front the scattering from small molecules and radicals will become increasingly sensitive to the $\mathrm{HAB}$ and these can be adequately estimated from chemical kinetic calculations.

The kinetic calculations were performed with the premixed flame module of CHEMKIN [64]. In addition to concentrations, the calculations also provided estimates of the flame temperatures at HAB WAXS data were acquired. For detailed chemistry the AramcoMech 1.3 model was selected [65] as this has been validated for the range of conditions in Ar- and $\mathrm{N}_{2}$-diluted flames. However, it is also of benefit to obtain rapid estimates of flame temperature and major species concentrations for on-the-fly analyses prior to more detailed simulations. To this end a very 
simple model which we refer to as a rudimentary chemical description (RCD) was also used. From the CHEMKIN simulations concentrations of the major species, mole fraction $>10^{-3}$, were extracted and the scattering profiles for each specie was calculated and incorporated into simulations of the experimental WAXS data as outlined earlier.

The RCD method used a very simple two equation system, Eqs. (8) and (9), that reproduced the main product concentrations, $\mathrm{C}_{2} \mathrm{H}_{2}$ and $\mathrm{CO}$, observed by $\mathrm{Xu}$ et al [66] in rich ethylene flames of similar $\mathrm{C} / \mathrm{O}$ ratios to the current work. However, it has to be taken into account that the Xu et al. flames were produced with a larger burner (60 mm diameter) and with an annular stabilization plate (30 mm i.d.) positioned $32 \mathrm{~mm}$ above the burner surface. Consequently, one may expect some deviations in the flow fields at $\mathrm{HAB}$ of 8 and $10 \mathrm{~mm}$ compared to the current work, but most probably not sufficient to prevent a qualitative comparison.

$$
\begin{aligned}
& \mathrm{C}_{2} \mathrm{H}_{4}+2 \mathrm{O}_{2} \rightarrow 2 \mathrm{CO}+2 \mathrm{H}_{2} \mathrm{O} \\
& \mathrm{C}_{2} \mathrm{H}_{4} \rightarrow \mathrm{C}_{2} \mathrm{H}_{2}+\mathrm{H}_{2}
\end{aligned}
$$

Calculations with both models were made at the experimental HABs. In order to understand how early chemistry would influence the fits of the experimental data calculations were also done for $\mathrm{HAB}=1 \mathrm{~mm}$ using the AramcoMech code. The flame temperatures obtained from the calculations, $T_{c a}$, and evaluated from WAXS, $T_{e v}$, are reported in Table 2. In Fig. 11 the main compositions of the flame gases of $A l$ and $N 1$, obtained from the chemical kinetic simulations are shown along with the corresponding RMSDs (including data points up to $q=6.5 \AA^{-1}$ ) of the fits to the experimental WAXS signals. In addition, to RCD and AramcoMech the experimental data 
of $\mathrm{Xu}$ et al. [64] were also used to estimate major flame species. The results demonstrate that the evaluated temperatures and RMSD improve as the chemistry gets more complete and the gas contains less oxygen.

Figures 12 and 13 give the best fits of the experimental and calculated $\gamma(q)$. For the comparative study using $A 1$ and $N 1$ we had set the estimated upper $q$-limit to $6.5 \AA^{-1}$ for the fitting procedure. For the complete sets of flames, $A 1-A 3$ and N1-N3, we had to decrease it to $5.2 \AA^{-1}$ to compare the quality of the fits for all the flames. The figures display the particle and precursor/graphene concentrations resulting from the fits, the relative amount of carbon present in the particles and small molecules along with the relative amounts of structured and amorphous species in the particles. PAH/Graphene appears to be the most important precursor species from the fitting of the experimental data. Previous WAXS studies on stabilized ethylene diffusion flames [49] indicated that fullerene, C60, may also be present, therefore initial trial simulations scattering from C60 were also included in the present work. However, these simulations indicate that in the freely propagating premixed flames presented here fullerenic species contribute little or nothing to the observed signal and that graphene has the most significant effect on the observed signal.

Table 3 gives a summary overview of the parameters retrieved from the WAXS experiments: The temperatures $T_{e v}, T_{c a}$, number concentration of the major flame species $N_{f}$, particle species $N_{p}$, and precursor/PAH/graphene species, $N_{g}$, are reported. The table also shows the relative amount of carbon bound in particles and molecules, $\mathrm{pm}$ and $\mathrm{mm}$, respectively in the last column. In more detail, $m m$ refers to the carbon mass of species given in size group (1), whereas that of $p m$ to that of the total carbon mass of species in groups (2) and (3) combined. 
The apparent temperature of the flame, $T_{f}$, which is given in Eq. (4a), was estimated from the chemical kinetic calculations, $T_{c a}$, and from the WAXS evaluation, $T_{e v}$. The resulting $T_{e v}$ were lower than the $T_{c a}$, for both the nitrogen and argon diluted flames. For the Ar-diluted flames the differences were relatively small, whereas for $\mathrm{N}_{2}$-diluted ones the deviations were larger and the differences in $T_{e v}$ and $T_{f}$ almost reached $200 \mathrm{~K}$, a fact, which is hard to rationalize at the present stage but maybe symptomatic of an experimental artifact.

The results from measurements with High Resolution Transmission Electron Microscopy (HRTEM) at the nCHREM facility at Lund University are displayed in Fig. 14 and with blow ups of details in Fig. 15. They agree with the results from the WAXS measurements in that they show how the $A 1^{\prime}$ condensed material is less dense and less graphitic than that from $N 1^{\prime}$. Furthermore, the particle units appear to be smaller and contain more strand-like structures that would agree with aliphatic components and graphene-like folded structures with a relatively low level of stacking, whereas the $N 1^{\prime}$ flame presents larger particle units with more densely packed strands that could be explained by graphitic nanostructures. Additional chemical information was obtained from Fourier Transform Infrared Spectroscopy and Microscopy (FTIRM) at the beamline D7, MAX-lab: Figure 16 shows markers for oxygenated particles species indicating that $A 1^{\prime}$ contains a stronger absorption peak than $N 1^{\prime}$ around $1720 \mathrm{~cm}^{-1}$, corresponding to carbonyl groups. This difference suggests that the graphene structures (identified by WAXS) for the A1-A3 flames may have been partially oxidized, and therefore were less prone to stacking depending on how the carbonyl groups are attached to the carbon skeletal structure. There is good agreement between the differences observed in the WAXS signals between the Ar and $\mathrm{N}_{2}$ diluted flames and 
those from analogous flames where samples were examined ex-situ by electron microscopy and infrared spectroscopy.

The particle species' absolute concentrations resulting from the WAXS experiments, $N_{p}$, are high compared to other studies. One reason is that WAXS has a high sensitivity towards small nanometer sized structures and particles compared with many other techniques but is hardly able, as explained later, to distinguish between free nanometer structures in the gas phase and structural components of larger particles in the current configuration of the set-up used for the experiments. The $N_{p}$ are also higher than reported from SAXS measurements in an ethylene diffusion flame [59], but within the same order of magnitude if hierarchic aggregation is taken into account and it is assumed that some of the WAXS signal derives from subunits of larger particles. For instance, the number concentrations of species with a size of $15 \AA$ in this work were typically around $10^{16} \mathrm{~cm}^{-3}$ for the nitrogen-diluted flames in the sooty regions. In terms of equivalent volume this corresponds to $\sim 5 \times 10^{14} \mathrm{~cm}^{-3}$ of $4 \mathrm{~nm}$ particles, whereas the corresponding number concentrations in [59] were $\sim 10^{14} \mathrm{~cm}^{-3}$ in the flame before any condensation effects were seen on a metal plate positioned $2 \mathrm{~mm}$ above the measurement point at $\mathrm{HAB}=15 \mathrm{~mm}$. The high number concentrations can be partially explained by a collisional rate based analysis assuming hierarchic type of aggregation and coagulation where particles mass is doubled at each collision event with almost $100 \%$ throughput on short time scales. Another possible source for excess carbon may be the release of deposits trapped in the sintered bronze plug that forms the burner, However, the burner was water cooled and this later source is very unlikely. 
In this work, the nanometer-sized structural species represented in the calculations were in the size range of 10-20 $\AA$ and they agreed reasonably with respect to the crystallographic size that can be obtained from the scattering profiles. For instance, representations of $\mathrm{AA}$ and $\mathrm{AB}$ with 352 atoms, i.e., four sheets of the graphene units separated by $3.4 \AA$ gave good results in comparison with the experimental results. The species could represent separate particles, but most probably corresponded to nanometer sized structural elements of primary particles or the fractal aggregates of particles commonly observed in late stages of soot production in flames. The experimental detector set-up did not allow any discrimination between the constituent units of agglomerates and agglomerates due to the limited $q$ range and resolution, but worked well in terms of reporting relative amount of carbon mass distributed between particles and small molecules. To discriminate between free and agglomerated particles it would be necessary to extend the $q$ range to lower $q$-values and conduct simultaneous WAXS and SAXS measurements.

For the Ar-diluted flames $N_{g}$, was high and corresponded to a substantial amount of graphene species, contrary to the case for the nitrogen diluted ones, which hardly showed any. The details close to $q=5.2 \AA^{-1}$ in the nitrogen flames might suggest graphene, however, the rest of the pattern does not. The results also show that the majority of carbon mass was present in the form of carbon particle species and precursors/graphene. Furthermore, as the temperature was raised in both the argon and nitrogen flames the mass of carbon present in particles increased. This trend is more clearly described by $p m$ as a function of $T_{e v}$ and $T_{c a}$, in Fig.17.

The uncertainty of the concentrations of particles was estimated by comparing two different fitting methods on the $N 1$ flame, i.e., using the method described in section 4.2 and an automatic and stable method based on the concept of optimization by simulated annealing by Kirkpatrick et 
al. [67]. The two different methods yielded a difference of 10-20\% for the amorphous particles concentrations and less than $2 \%$ for the graphitic particles. The effect of the uncertainty in background from the detector signals was estimated from the $A l$ flame. The variations in absolute species concentrations and temperature were less than $20 \%$ and $1.5 \%$, respectively, while differences in the relative composition of particle and precursor species was less than 5\% for the fitting scheme describe in section 4.2.

\subsection{Particle and precursor sensitivity analysis}

This section describes how the quality of the fits depends on the choice of structural species of particles and precursors. The analysis is for reasons of simplicity based on the experimental data for the $A 1$ and $N 1$ flames.

Figure 18 displays how the quality of the fit depends on the composition of the structural species for argon-diluted flame $A l$ and similar results are given in Fig. 19 for the $N 1$ flame. Fig. 18 (a) shows the best fit with the AramcoMech 1.3 model providing the small molecule compositions. In Fig. 18 (b)-(g) the particle parameters were changed while maintaining the same temperature and number of carbon atoms. The results show that the fits improve when graphite particles are replaced by single sheet graphene species. This is particularly evident for the $q$ region around 5.2 $\AA^{-1}$, which thus may be proposed as a signature position for the presence of graphene in these tests. Amorphous chains with C-C $=1.42 \AA$ (Ch_1) did not yield as good results as with C-C 1.54 $\AA$ (Ch_2). In addition the specific superstructures of the chosen chains gave better results than a representation given by a statistical average, Av_2, of many random calculated structures. The main scattering peak below $q=1.75 \AA^{-1}$, was weaker and more shifted to lower $q$ values compared to the nitrogen diluted flames. This could also correspond to less stacking of molecules 
or graphene planes and with larger separation between the subunits. For instance for flame $A 1$, the fits were not improved by adding graphite whereas the reverse was true for $N 1$ where $10-20 \AA$ sized graphitic nanoparticles $\mathrm{AA}$ and $\mathrm{AB}$ had to be incorporated in the scattering calculations. Including $\mathrm{AA}$ or $\mathrm{AB}$ alone did not yield as good fits as when a mixture was used, although using just $\mathrm{AB}$ yielded better fits than only AA. The sensitivity of the fits to the morphology of the carbon chains was not easily discerned by eye, but the RMSD was the lowest for the case of an average representation, $A v \_1$, of amorphous chain with the bond distance $1.42 \AA$ and $C h \_2$ for the corresponding one with the bond length $1.54 \AA$. Both bond length chains had to be included. The superstructure of Ch_2 seemed to be an important ingredient for the description of the contribution from "aliphatic" chains. For the $\mathrm{N}_{2}$-diluted flames, which showed more details in the scattering than for the Ar-diluted ones, the fits were less good. It may therefore be questionable if one should choose the fit with the lowest RMSD for the $\mathrm{N}_{2}$ diluted flames without any further analysis on details as the most significant representation of the true conditions in the flame. More measurements will be required to give a definite answer. In any case the results from the best fits are consistent with known properties of graphite.

The overall results based on the comparison between the Ar- and $\mathrm{N}_{2}$-diluted flames agree with the general trends described by molecular dynamics calculations $[14,15]$ and previous WAXS experiments $[48,49,58-60]$ on plate stabilized flames: lower temperatures yield more planar or graphitic structures (with $s p^{2}$ ) and higher temperatures more curved, less structured and amorphous structures with a higher content of $s p^{3}$ hybridization. There are some other interesting aspects that result from the evaluation of the argon and nitrogen flames: the concentration of particulate carbon was the highest for the highest temperature and graphene was found in the argon-diluted flames to be more abundant at $\mathrm{HAB}=8 \mathrm{~mm}$ than at $10 \mathrm{~mm}$. 


\section{Conclusion}

This work has presented an in-situ study and a method to characterize and measure carbon species in sooting atmospheric pressure premixed flames, taking into account effects from high temperature chemistry. The flame temperatures and the concentrations of nanometer sized structural carbon species such as graphene, graphitic, and amorphous, and major small molecular flame species were obtained by combining WAXS measurements and detailed chemical and scattering calculations. The technique is able to resolve signals from nanometer sized species, which are hard to visually resolve from the molecular contribution when they are analyzed from the measured scattering intensities, but appear clearer when they are first normalized against the intensities from a well-defined cold gas flow. The relatively high signal-to noise achieved with the photon flux on the order of $10^{16}$ photons $\mathrm{s}^{-1}$ has demonstrated the performances of the technique. The agreement between scattering measurements and modeling by the direct use of commercial chemical codes without predefining flame temperatures is generally very good. For both the nitrogen and argon diluted flames the evaluated temperatures are lower than the ones obtained from the calculations. For the nitrogen diluted flames there were considerable deviations around $200 \mathrm{~K}$, which are hard to explain at this stage. The evaluations not only told us of the particle composition, e.g., that carbon particles exhibit both structured and unstructured carbon and that argon-diluted flames presented more unstacked graphene-like structures whereas nitrogen-diluted more graphitic, but also provided information related to flame chemistry. For instance, we found that the measurements points corresponded to a late stage of the reaction between the premixed fuel and the oxidant that was supplied through the burner surface. A more detailed study will yield important feedback to modelers, in particular concerning differences in temperature between argon and nitrogen diluted flames. To put the interpretation onto a more 
quantitative footing it is also desirable to measure temperature profiles for each flame, although, as shown a qualitative interpretation can be obtained without the temperature profile.

The RCD scheme with two reactions could reproduce the experimental data reasonably well. This is of great value, because the model can be easily applied to a wide variety of rich fuel/air or fuel/oxygen mixtures. At the very least the simple model can be used to find temperature and concentration estimates as a starting point for more advanced calculations of which the ones using the AramcoMech 1.3 code good in our tests.

The studies have also shown that soot formation can be strongly spatially inhomogeneous, since we found substantial density variations evidenced in connection to the soot rich regions of the premixed flames. This phenomenon should be considered in further studies and soot modeling. The very intense radiation at coming $4^{\text {th }}$ generation synchrotron and free electron laser facilities will provide narrow beams with a extraordinary levels of coherence and photon fluxes that will give highly increased sign-to-noise ratios due to enhanced photon statistics that will get better the detection limits of nanoparticles and also yield a considerably higher spatial resolution to study the inhomogeneity in connection to soot formation. The temporal resolution will also strongly improve by the use of very short X-ray pulses so that chemical and particle formation dynamics can be studied in reactors.

\section{Acknowledgements}

We gratefully acknowledge Raghu Sivaramakrishnan and Nicole J. Labbe for the chemical calculations and the group that installed the silicon mirror on BESSERC 12- ID-C: Mark A. Beno, Randall E. Winans, Mark S. Engbretson, Guy Jennings, Charles A. Kurtz, Nadia E. 
Leyarovska, Lynn W. Ribaud, and Soenke Seifert. We are grateful for the care taken by Traffic Analysis Group with regard to the transport of the equipment. The use of the Advanced Photon Source was supported by the U. S. Department of Energy, Office of Science, Office of Basic Energy Sciences, under Contract No. DE-AC02-06CH11357. Robert Tranter is grateful to Office of Basic Energy Sciences, Division of Chemical Sciences, Geosciences, and Biosciences, U.S. Department of Energy, under contract number DE-AC02-06CH11357. We also gratefully acknowledge Andreas Arvidsson for the automatic fitting calculations based on the simulated annealing. Frederik Ossler and Sophie E. Canton are grateful for the support given by the Swedish Research Council, the Crafoord Foundation and the Centre of Combustion Science and Technology (CECOST). 


\section{References}

1. Broday DM, Rosenzweig R. Deposition of fractal-like soot aggregates in the human respiratory tract. J. Aerosol Sci. 42 (2011) 372-386.

2. Terzano C, di Stefano F, Conti V, Graziani E, Petroianni A. Air pollution ultrafine particles: toxicity beyond the lung. Euro. Rev. Med. Pharm. Sci. 14 (2010) 809-821.

3. Donaldson K, Tran L, Jimenez LA, Duffin R, Newby DE, Mills N, et al.. Combustionderived nanoparticles: A review of their toxicology following inhalation exposure. Part. Fibre Tox. 2:10 (2005). doi:10.1186/1743-8977-2-10

4. Anikiev VV, Kolesov GM, Pavlov AA. Impact of anthropogenic and natural factors on the air quality above the Northern Caspian Sea and the ecological risk level for the human population in the coastal zone. Geochem. Int. 49 (2011) 154-169.

5. Gaga EO, Ari A. Gas-particle partitioning of polycyclic aromatic hydrocarbons (PAHs) in an urban traffic site in Eskisehir, Turkey. Atm. Res. 9 (2011) 207-216.

6. Myhre G, Fuglestvedt JS, Berntsen TK, Lund MT. Mitigation of short-lived heating components may lead to unwanted long-term consequences. Atm. Env. 45 (2011) 61036106.

7. Spracklen DV, Carslaw KS, Pöschl U, Rap A, Forster PM. Global cloud condensation nuclei influenced by carbonaceous combustion aerosol. Atmos. Chem. Phys. 11 (2011) 9067-9087.

8. Junkermann W, Vogel B, Sutton MA. The climate penalty for clean fossil fuel combustion, Atmos. Chem. Phys. 11 (2011) 12917-12924.

9. Bockhorn H, D’Anna A, Sarofim AF, Wang H, (Eds). Combustion Generated Fine Carbonaceous Particles. KIT Scientific Publishing; Karlsruhe, 2009. 
10. Desgroux P, Mercier X, Thomson KA. Study of the formation of soot and its precursors in flames using optical diagnostics. Proc. Combust. Inst. 34 (2013) 1713-1738.

11. Violi A, Voth GA,. Sarofim AF. The relative roles of acetylene and aromatic precursors during soot particle inception. Proc. Combust. Inst. 30 (2005) 1343-1351.

12. Violi A, Izvekov S. Soot primary particle formation from multiscale coarse-grained molecular dynamics simulation. Proc. Combust. Inst. 31 (2007) 529-537.

13. Richter H, Howard JB. Formation of polycyclic aromatic hydrocarbons and their growth to soot - a review of chemical reaction pathways. Progr. Energy Combust. Sci. 26 (2000) 565-608.

14. Yamaguchi S, Maruyama S. A molecular dynamics simulation of the fullerene formation process. Chem. Phys. Letters 286 (1998) 343-349.

15. Yamaguchi Y, Colombo L, Piseri P, Ravagnan L, Milani P. Growth of sp-sp2 nanostructures in a carbon plasma. Phys. Rev. B 76 (2007) 134119 (7).

16. Fugaciu F, Hermann H, Seifert G. Concentric-shell fullerenes and diamond particles: A molecular-dynamics study. Phys. Rev. B 60 (1999) 10711-10714.

17. Hermann H, Fugaciu F, Seifert G. Towards controlled production of specific carbon nanostructures - a theoretical study on structural transformations of graphitic and diamond particles. Appl. Phys. Letters 79 (2001) 63-65.

18. Dobbins RA, Govatzidakis GJ, Lu W, Schwartzman AF, Fletcher RA. Carbonization rate of soot precursor particles. Combust. Sci Technol. 121 (1996) 103-121.

19. Le Normand F, Constant L, Ehret G, Romeo M, Charai A, Saikaly W, et al.. Investigation of carbon aggregates (onions) formed on copper under the conditions of diamond chemical vapour deposition. Philos. Mag. A 79 (1999)1739-1756. 
20. Zhu WZ, Miser DE, Chan WG, Hajaligol MR. Characterization of combustion fullerene soot, C60, and mixed fullerene. Carbon 42 (2004)1463-1471.

21. Grieco WJ, Howard JB, Rainey LC, Vander Sande JB. Fullerenic carbon in combustiongenerated soot. Carbon 38 (2000) 597-614.

22. Goel A, Hebgen P, Vander Sande JB, Howard JB. Combustion synthesis of fullerenes and fullerenic nanostructures. Carbon 40 (2002) 177-182.

23. Lee TH, Yao N, Chen TJ, Hsu WK. Fullerene-like carbon particles in petrol soot. Carbon 40 (2002) 2275-2279.

24. Sgro LA, Basile G, Barone AC, D’Anna A, Minutolo P, Borghese A, et al.. Detection of combustion formed nanoparticles. Chemosphere 51 (2003) 1079-1090.

25. Zeinalipour-Yazdi C, Pullman DP. A new interpretation of the scanning tunneling microscope image of graphite. Chem. Phys. 348 (2008) 233-236.

26. Solís-Fernández P, Paredes JI, Martínez-Alonso A, Tascón JMD. New atomic-scale features in graphite surfaces treated in a dielectric barrier discharge plasma. Carbon 46 (2008) 1364-1367.

27. Huang CP, Su CC, Ho MS. Intramolecular structures of C60 and C84 molecules on Si(1 1 1) $-7 \times 7$ surfaces by scanning tunneling microscopy. Appl. Surf. Sci. 254 (2008) $7712-$ 7717.

28. Tapasztò L, Nemesincze P, Osváth Z, Bein MC, Darabont AL, Biró LP. Complex superstructure patterns near defect sites of carbon nanotubes and graphite. Physica E 40 (2008) 2263-2267. 
29. De Angelis F, Patrini M, Das G, Maksymov I, Galli M, Businaro L, et al.. A hybrid plasmonic-photonic nanodevice for label-free detection of a few molecules. Nano Letters 8 (2008) 2321-2327.

30. Laverdant J, Buil S, Quélin X. Local field enhancements on gold and silver nanostructures for aperture near field spectroscopy. J. Lumin. 127 (2007) 176-180.

31. Downes A, Salter D, Elfick A, Simulations of atomic resolution tip-enhanced optical microscopy, Opt. Exp. 229 (2006) 11324-11329.

32. Kharintsev SS, Hoffmann GG, Loos J, de With G, Dorozhkin PS, Salakhov M Kh, Subwavelength-resolution near-field Raman spectroscopy. Atoms Mol. Opt. 105 (2007) 909915.

33. Plech A, Kotaidis V, Istomin K, Wulff M, Small-angle pump-probe studies of photoexcited nanoparticles. J. Synchrotron Rad. 14 (2007) 288-294.

34. Li B,. Li Zh, Yang J, Hu JG, STM studies of single molecules: molecular orbital aspects. Chem. Commun., 47 (2011) 2747-2762.

35. Niu T, Li A, Phys. Exploring single molecules by scanning probe microscopy: Porphyrin and phthalocyanine. Chem. Letters, 4 (2013) 4095-4102.

36. Sgro LA, De Filippo A, Lanzuolo G, D’Alessio A. Characterization of nanoparticles of organic carbon (NOC) produced in rich premixed flames by differential mobility analysis. Proc. Combust. Inst. 31 (2007) 631-638.

37. Abid AD, Heinz N, Tolmachoff ED, Phares DJ, Campbell CS, Wang H. On evolution of particle size distribution functions of incipient soot in premixed ethylene-oxygen-argon flames. Combust. Flame 154 (2008) 775-788. 
38. Shaddix CR. Correcting thermocouple measurements for radiation loss: A critical review, Proceedings of the 33rd National Heat Transfer ConferenceAugust 15-17, 1999, Albuquerque, New Mexico.

39. Weilmünster P, Keller A, Homann KH. Large molecules, radicals, ions, and small soot particles in fuel-rich hydrocarbon flames part I: positive ions of polycyclic aromatic hydrocarbons(PAH) in low-pressure premixed flames of acetylene and oxygen. Combust. Flame 116 (1999) 62-83.

40. Grotheer HH, Pokorny H, Barth KL, Thierly K-L, Aigner M. Mass spectrometry up to 1 million mass units for the simultaneous detection of primary soot and of soot precursors (nanoparticles) in flames. Chemosphere 57 (2004) 1335-1342.

41. Grotheer HH, Wolf K, Hoffmann K. Photoionization mass spectrometry for the investigation of combustion generated nascent nanoparticles and their relation to laser induced incandescence. Appl. Phys. B 104 (2011) 367-383

42. Eckbreth NAC. Laser diagnostics for combustion temperature and species, $2^{\text {nd }}$ Ed., Gordon and Breach, Amsterdam, 1996.

43. Kohse-Höinghaus K, Jeffries JB. (Eds), Applied combustion diagnostics, Taylor and Francis, London, 2002.

44. Borisevich A. Vozbuzhdenye Sostoyanya Slozhnykh Molekul v Gazovoy Faze (Excited States of Complex Molecules in the Gas Phase) (in Russian); Nauka y Tekhnika: Minsk, 1967.

45. Ossler F, Metz T, Aldén M. Picosecond laser-induced fluorescence from gas-phase polycyclic aromatic hydrocarbons at elevated temperatures. I. Cell measurements. J. Appl. Phys. B 72 (2001) 465-478. 
46. Ossler F, Metz T, Aldén M. Picosecond laser-induced fluorescence from gas-phase polycyclic aromatic hydrocarbons at elevated temperatures. II. Flame-seeding measurements. J. Appl. Phys. B 72 (2001) 479-489.

47. Braun A, Huggins FE, Shah N, Chen Y, Wirick S, Mun SB et al,, Advantages of soft Xray absorption over TEM-EELS for solid carbon studies - a comparative study on diesel soot with EELS and NEXAFS. Carbon 43 (2005) 117-124.

48. Ossler F, Larsson J. Exploring the formation of carbon-based molecules, clusters and particles by in situ detection of scattered radiation. Chem. Phys. Lett. 387 (2004) 367371.

49. Ossler F, Larsson J. Measurements of the structures of nanoparticles in flames by in situ detection of scattered X-ray radiation. J. Appl. Phys. 98 (2005) 114317.

50. England WA. An in situ X-ray small-angle scattering study of soot morphology in Flames. Combust. Sci. Technol. 46 (1986) 83-93.

51. Hessler JP, Seifert S, Winans RE. Spatially resolved small-angle X-ray scattering studies of soot inception and growth. Proc. Combust. Inst. 29 (2002) 2743-2748.

52. Hessler JP, Seifert S, Winans RE, Fletcher TH. Small-angle X-ray studies of soot inception and growth. Faraday Discuss. 119 (2001) 395-407.

53. di Stasio S, Mitchell JBA, LeGarrec JL, Biennier L, Wulff M. Synchrotron SAXS (in situ) identification of three different size modes for soot nanoparticles in a diffusion flame. Carbon 44 (2006) 1267-1279.

54. Mitchell JBA, Courbe J, Florescu-Mitchell AI, di Stasio S, Weiss T. Demonstration of soot particle resizing in an ethylene flame by small-angle X-ray scattering ., J. Appl. Phys. 100 (2006) 124918. 
55. Sztucki M, Narayanan T, Beaucage G. In situ study of aggregation of soot particles in an acetylene flame by small-angle X-ray scattering. J. Appl. Phys. 101 (2007) 114304.

56. Beaucage G, Kammler HK, Mueller R, Strobel R, Agashe N, Pratsinis SE, et al..Nat. Mater. 3 (2004) 370-373.

57. Braun A, Shah N, Huggins FE, Kelly KE, Sarofim A, Jacobsen C, et al.. X-ray scattering and spectroscopy studies on diesel soot from oxygenated fuel under various engine load conditions. Carbon;43 (2005) 2588-2599.

58. Vallenhag L, Canton SE, Ossler F. In-situ combined small- and wide-angle X-Ray scattering for the study of nanoparticle dynamics in an ethylene diffusion flame stabilized by a metal plate, Seventh Mediterranean Combustion Symposium, Chia Laguna, Italy, September 11-15, 2011.

59. Ossler F, Vallenhag L, Canton SE, Mitchell JBA, LeGarrec JL, Sztucki M, di Stasio S.Dynamics of incipient carbon particle formation in a stabilized ethylene flame by in situ extended-small-angle and wide-angle X-ray scattering. Carbon 51 (2013) 1-19.

60. Ossler F, Canton SE, Larsson J. X-ray scattering studies of the generation of carbon nanoparticles in flames and their transition from gas phase to condensed phase. Carbon 47 (2009) 3498-3507.

61. Hubbell JH, Veigele WmJ, Briggs EA, Brown RT, Cromer DT, Howerton RJ. Atomic form factors, incoherent scattering functions and photon scattering cross sections. J. Phys. Chem. Ref. Data 4 (1975) 471-538.

62. Chakarova-Käck SD, Vojvodic A, Kleis J, Hyldegaard P, Schröder E. Binding of polycyclic aromatic hydrocarbons and graphene dimers in density functional theory. New J. Phys. 12 (2010) 013017. 
63. McKenna WW. Interaction between detonation waves and flowfields. AIAA Journal 5 (1967) 868-873.

64. CHEMKIN Release 10131 (x64), Reaction Design: San Diego, 2013.

65. Metcalfe WK, Burke S.M, Ahmed SS, Curran HJ. Intl. J. Chemical Kinetics 45 (2013) 638-675. Release date: August $26^{\text {th }} 2013$.

66. Xu F, Sunderland PB, Faeth GM. Soot formation in laminar premixed ethylene/air flames at atmospheric pressure. Combust Flame, Combust. Flame 108 (1997) 471-493.

67. Kirkpatrick S, Gelatt CD. Jr., Vecchi MP. Optimization by Simulated Annealing. Science, New Series 220 (1983) 671-680. 


\section{Tables}

Table 1

\begin{tabular}{|c|c|c|c|c|c|c|c|c|}
\hline & A1 & A2 & A3 & Aref & N1 & N2 & N3 & Nref \\
\hline $\begin{array}{l}\text { Co- } \\
\text { flow-N2 } \\
(\mathrm{l} / \mathrm{min})\end{array}$ & 8.5 & 6.8 & 8.5 & 8.5 & 7.6 & 7.6 & 6.8 & 6.1 \\
\hline $\begin{array}{l}\mathrm{C}_{2} \mathrm{H}_{4} \\
(\mathbf{l} / \mathbf{m i n})\end{array}$ & 0.21 & 0.20 & 0.23 & 0.00 & 0.24 & 0.24 & 0.21 & 0.00 \\
\hline $\begin{array}{l}\mathrm{O}_{2} \\
(1 / \mathrm{min})\end{array}$ & 0.26 & 0.26 & 0.26 & 0.26 & 0.26 & 0.26 & 0.26 & 0.29 \\
\hline $\begin{array}{l}\text { Fuel-Ar } \\
\text { (l/min) }\end{array}$ & 1.02 & 0.88 & 1.02 & 1.02 & 0.00 & 0.00 & 0.00 & 0.00 \\
\hline $\begin{array}{l}\text { Fuel-N } 2 \\
\text { (l/min) }\end{array}$ & 0.00 & 0.00 & 0.00 & 0.00 & 0.58 & 0.63 & 0.58 & 0.61 \\
\hline $\mathrm{C} / \mathrm{O}$ & 0.83 & 0.76 & 0.90 & 0.00 & 0.95 & 0.95 & 0.83 & 0.00 \\
\hline$\Phi$ & 2.5 & 2.3 & 2.7 & 0.0 & 2.9 & 2.9 & 2.5 & 0.0 \\
\hline $\begin{array}{l}\text { Gas } \\
\text { velocity } \\
(\mathrm{cm} / \mathrm{s})\end{array}$ & 8.78 & 7.83 & 8.88 & 7.52 & 6.35 & 6.67 & 6.17 & 5.27 \\
\hline $\begin{array}{l}\text { Mole } \\
\text { fraction, } \\
\mathbf{x}_{\mathbf{i}}, \text { of } \\
\mathrm{C}_{2} \mathbf{H}_{4}\end{array}$ & 0.14 & 0.14 & 0.15 & 0.00 & 0.23 & 0.22 & 0.20 & 0.00 \\
\hline
\end{tabular}

Table 1: Flow conditions for the Al-A3 and N1-N3 flames. 


\begin{tabular}{|l|l|l|l|l|l|}
\hline Calc. & Source & $\begin{array}{l}\mathbf{A 1} \\
\mathbf{H A B} \\
(\mathbf{m m})\end{array}$ & $\begin{array}{l}\mathbf{A 1 ~ T}_{\mathbf{c a}}(\mathbf{K}) / \\
\mathbf{T}_{\mathbf{e v}}(\mathbf{K})\end{array}$ & $\begin{array}{l}\mathbf{N 1} \\
\mathbf{H A B} \\
(\mathbf{m m})\end{array}$ & $\begin{array}{l}\mathbf{N 1} \mathbf{T}_{\mathbf{c a}}(\mathbf{K}) / \\
\mathbf{T}_{\mathbf{e v}}(\mathbf{K})\end{array}$ \\
\hline $\mathbf{A}$ & RCD & $*$ & $* * / 1770$ & $*$ & $* * / 1500$ \\
\hline $\mathbf{B}$ & Xu et al. & $*$ & $* * / 1770$ & $*$ & $* * / 1500$ \\
\hline $\mathbf{C}$ & Aramco 1.3 & 8 & $1764 / 1730$ & 10 & $1644 / 1428$ \\
\hline $\mathbf{D}$ & Aramco 1.3 & 1 & $1417 / 1795$ & 1 & $1337 / 1488$ \\
\hline
\end{tabular}

Table 2: The calculated and evaluated temperatures are reported for the best fits using the data sets (A)-(D) for the flames $A l$ and Nl. *Height not specified or relevant for the comparison; **No calculated temperatures. 


\begin{tabular}{|l|l|l|l|l|l|l|l|l|}
\hline & Tev (K) & Tca (K) & $\begin{array}{l}\mathbf{N}_{\mathbf{f}}\left(\mathbf{c m}^{-\mathbf{3}}\right) \\
\times \mathbf{1 0 ^ { - 1 8 }}\end{array}$ & $\begin{array}{l}\mathbf{N}_{\mathbf{p}}\left(\mathbf{c m}^{-\mathbf{3}}\right) \\
\times \mathbf{1 0}^{-15}\end{array}$ & $\begin{array}{l}\mathbf{N}_{\mathbf{g}}\left(\mathbf{c m}^{-\mathbf{3}}\right) \\
\times \mathbf{1 0 ^ { - 1 5 }}\end{array}$ & $\mathbf{p m} \mathbf{m m}$ & $\begin{array}{l}\text { RMSD } \\
\times \mathbf{1 0 ^ { 4 }}\end{array}$ & $\mathbf{\Phi}$ \\
\hline A1 & 1730 & 1764 & 4.22 & 13.2 & 7.23 & $0.83 / 0.17$ & 6.25 & 2.5 \\
\hline A2 & 1739 & 1794 & 4.20 & 15.2 & 5.70 & $0.85 / 0.15$ & 7.71 & 2.3 \\
\hline A3 & 1675 & 1769 & 4.36 & 14.3 & 5.74 & $0.84 / 0.16$ & 8.84 & 2.7 \\
\hline N1 & 1432 & 1644 & 5.11 & 9.25 & 0.00 & $0.65 / 0.35$ & 12.1 & 2.9 \\
\hline N2 & 1492 & 1657 & 4.91 & 10.2 & 0.00 & $0.69 / 0.31$ & 13.8 & 2.9 \\
\hline N3 & 1501 & 1690 & 4.88 & 11.2 & 0.00 & $0.72 / 0.28$ & 14.3 & 2.5 \\
\hline
\end{tabular}

Table 3:. $T_{e v}$ and $T_{c a}$ are the evaluated and calculated temperatures for $T_{f}$ (defined in Eq. (4a)). $T_{c a}$ are from simulations with AramcoMech 1.3; $N_{f}, N_{p}$, and $N_{g}$ are the volume concentrations for the flame major species, nanoparticles, and precursors/graphene, respectively; $\mathrm{pm} / \mathrm{mm}$ are the relative carbon masses for particles and molecules, respectively; RMSD is the root mean square deviation of the fit 
150916 Time 16:20

\section{Figures and captions}




\section{Fig.1}
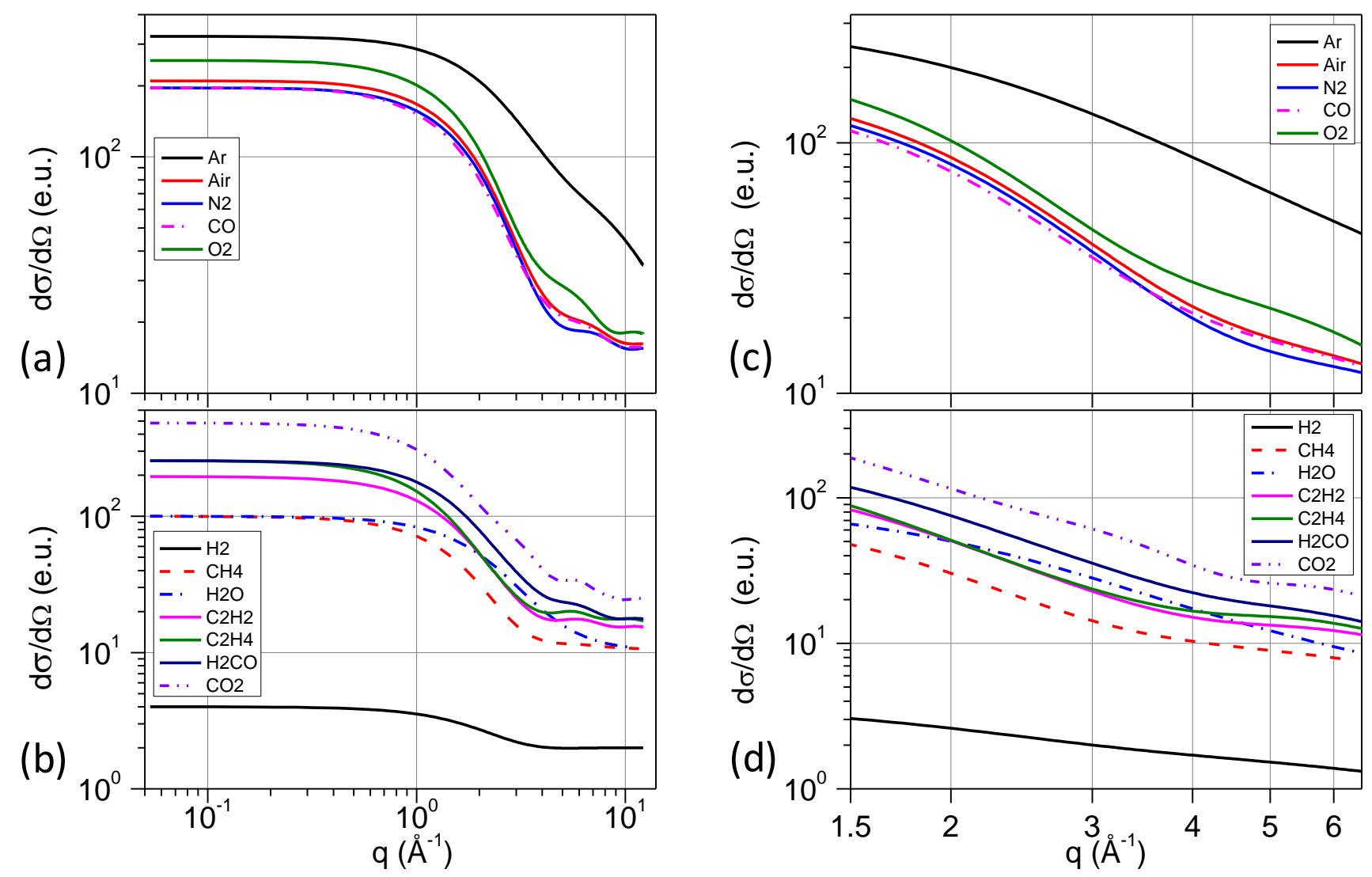

Fig.1: (a) and (b) Differential scattering cross sections for the major species of the overall major species differential cross section $\left(\varphi=90^{\circ}\right)$; (c) and (d) The corresponding cross section for $\varphi=$ $50^{\circ}$ used in the experiments taking into account the view field of the detector and the significant $\mathrm{q}$ range for the data evaluation. The graphs' axes are in $\log -\log (\mathrm{y}, \mathrm{x})$ scales. 
Fig.2

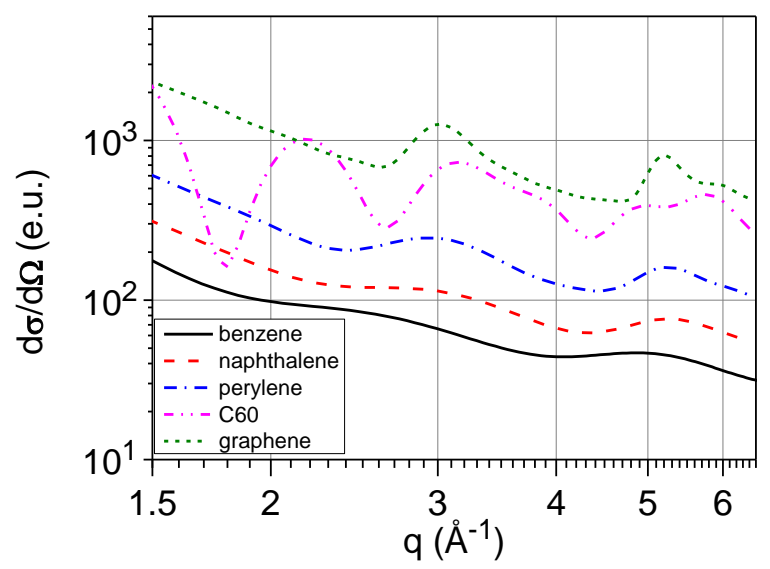

Fig.2: Precursors. Differential cross sections of molecules and carbon structures with less than 100 carbon atoms. The graph's axes are in $\log -\log (\mathrm{y}, \mathrm{x})$ scales. 
(a)
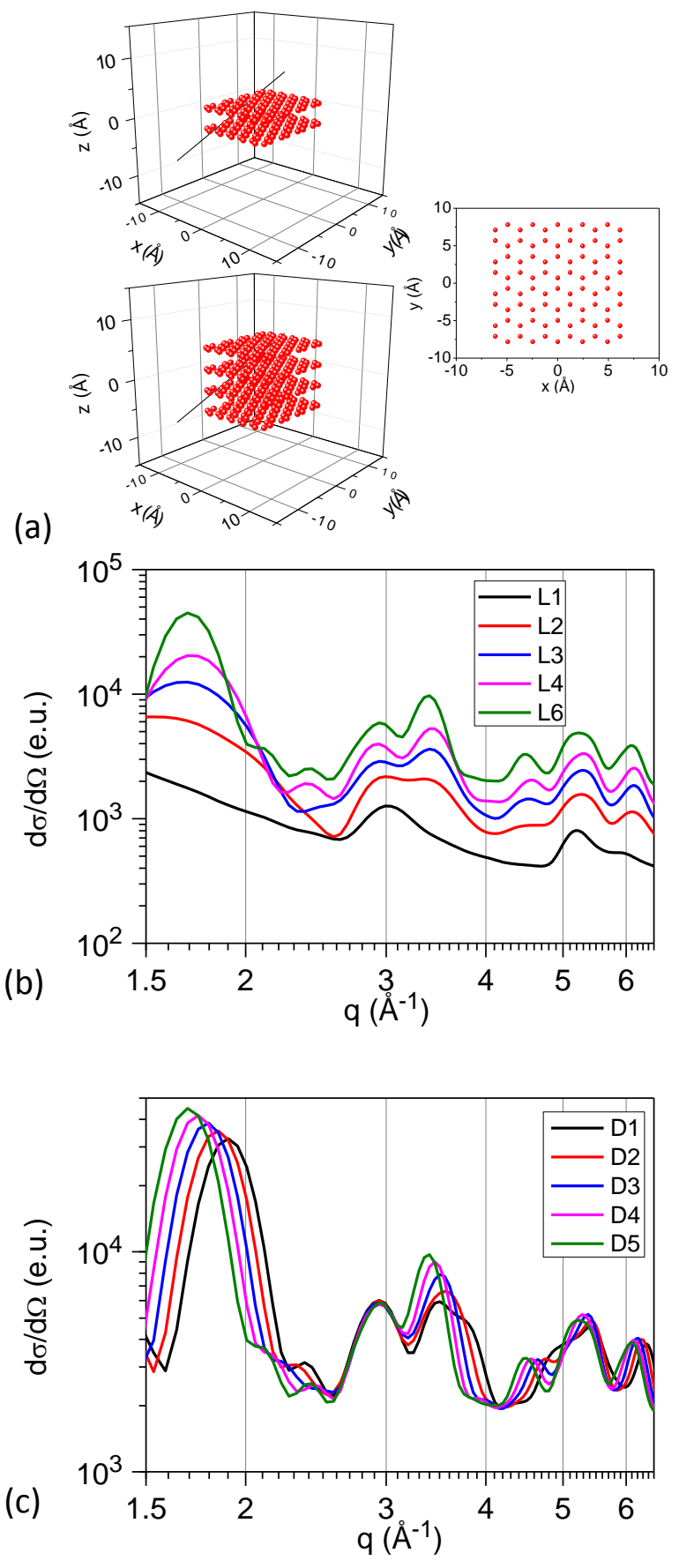

Fig.3: Atomic structures and $\boldsymbol{d} \boldsymbol{\sigma} / \boldsymbol{d} \boldsymbol{\Omega}$ for AA graphitic nanometer sized species: (a) Example 2 and 4 layer structures; (b) cross sections for 1-6 layers (L1-L6) in AA with each layer separated by $3.6 \AA$; (c) cross sections for 6 layer structures of type AA with layers separated by 3.3, 3.4, 3.5, 3.6 and 3.7 $\AA$ (D1-D5 respectively). 

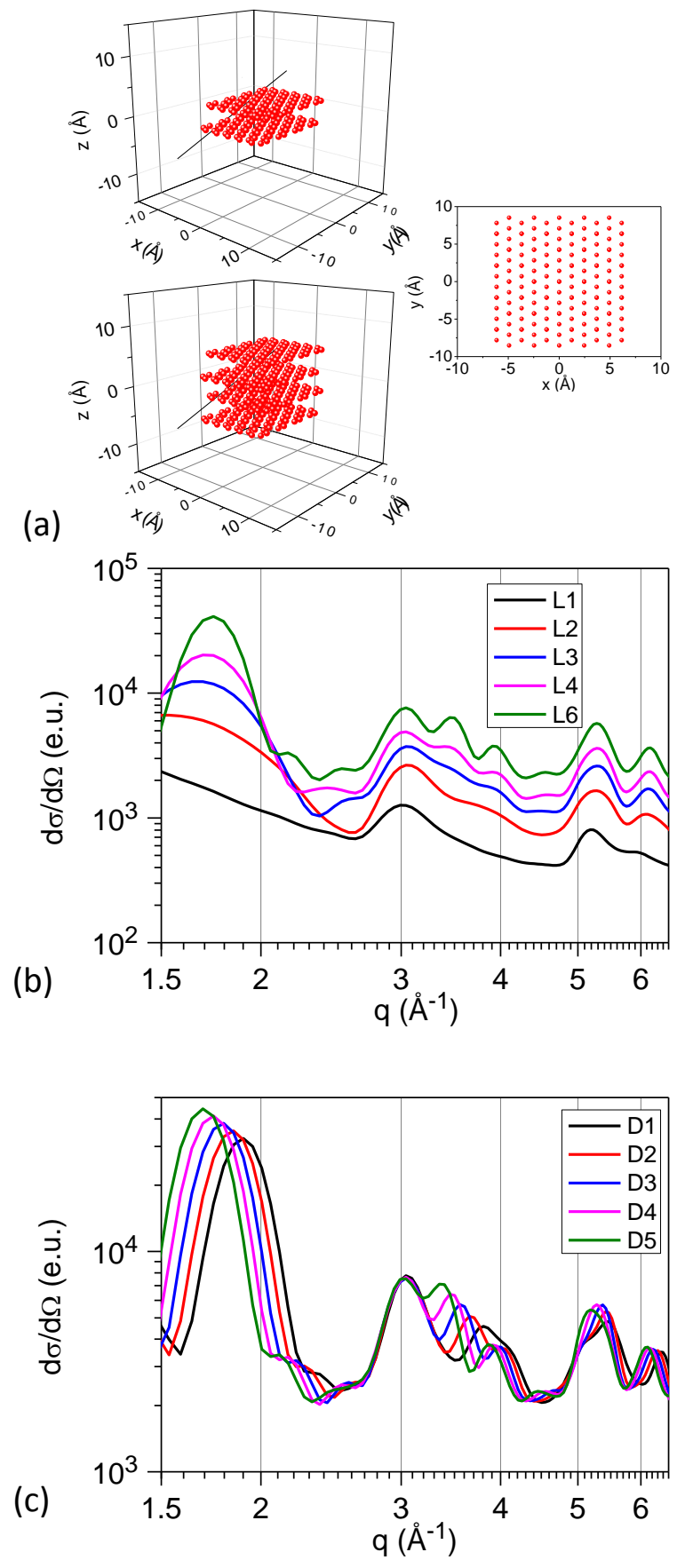

Fig. 4 Atomic structures and $\boldsymbol{d} \sigma / \boldsymbol{d} \boldsymbol{\Omega}$ for $\mathrm{AB}$ graphitic nanometer sized species: (a) Example 2 and 4 layer structures; (b) cross sections for 1-6 layers (L1-L6) in AA with each layer separated by $3.6 \AA$; (c) cross sections for 6 layer structures of type $A B$ with layers separated by 3.3, 3.4, 3.5, 3.6 and 3.7 ̊ (D1-D5) respectively. 
150916 Time 16:20

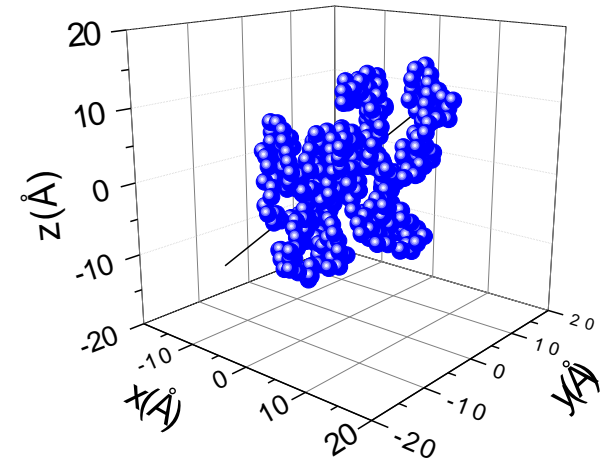

(a)

(b)
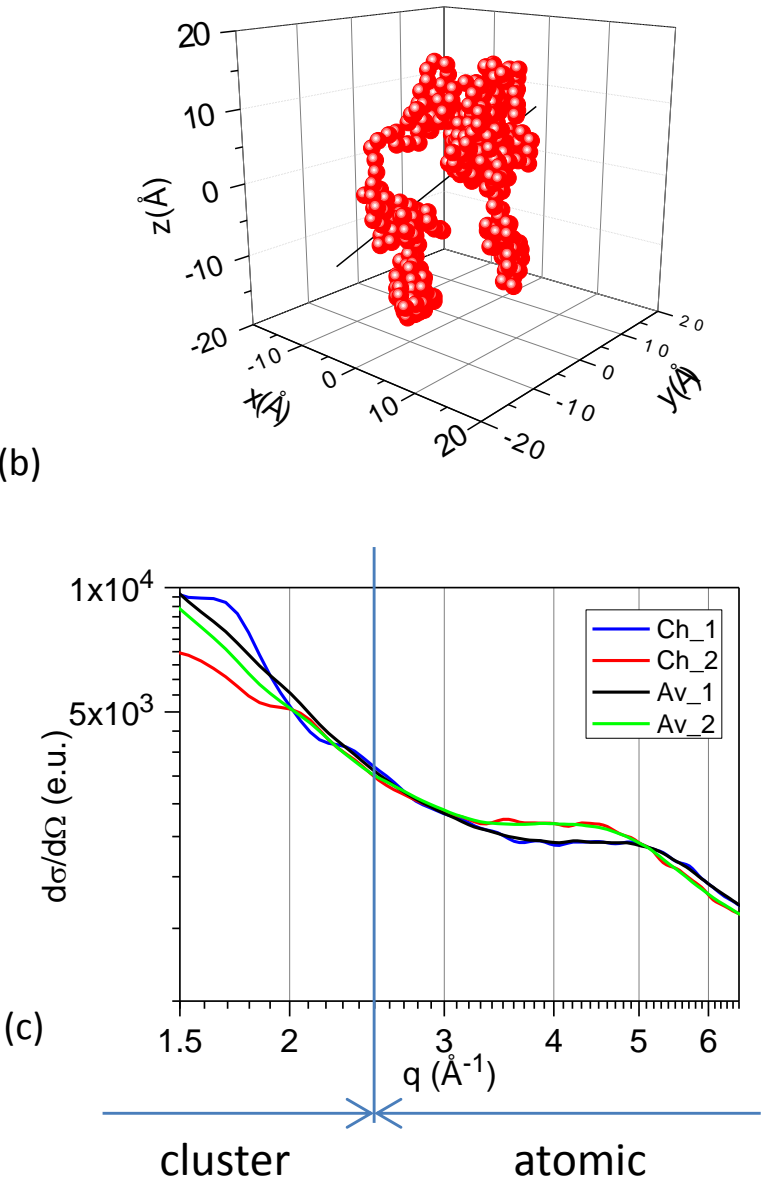
Fig.5 Amorphous chains: (a) (Ch_1) with c-c bond length of $1.42 \AA$; (b) structures of amorphous chains (Ch_2) with c-c bond length off $1.54 \AA$ (Ch_2); (c) Differential cross sections for the amorphous structures (a), (b) and averages of cross sections (Av_1 and Av_2) from stochastic calculations using the two different bond lengths. Two characteristic scattering regions can be observed: the cluster resolution mode for $q<2.5 \AA^{-1}$ the atomic level resolution mode for $q>2.5$ $\AA^{-1}$. 


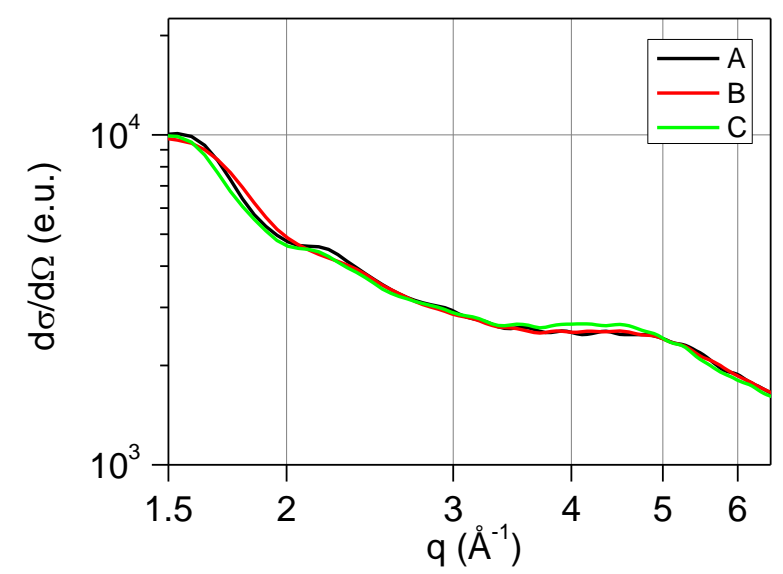

Fig.6: The effect of bond lengths on scattering cross sections. In all cases the base structure is that shown in Fig. 5a for Ch_1, but with various combinations of bond lengths are used: Curve A represents alternating long and short bonds, B is the average of two structures one of which contains only long bonds and the other short bonds, $\mathrm{C}$ is for the same chain, but with a bond length that is constant and corresponds to that of the average for A and B. 


\section{Fig. 7}

(a)

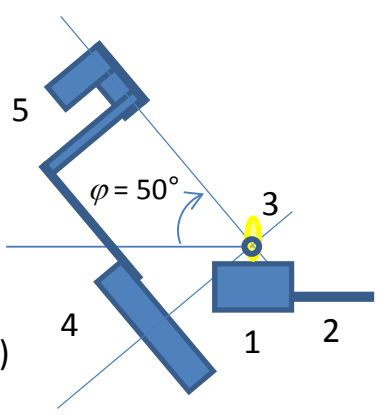

Argon dilution

A1

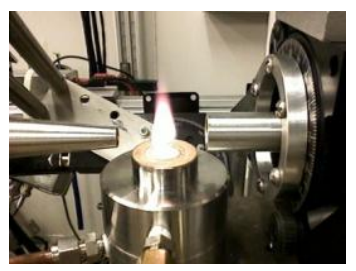

(c)
(d)

N1
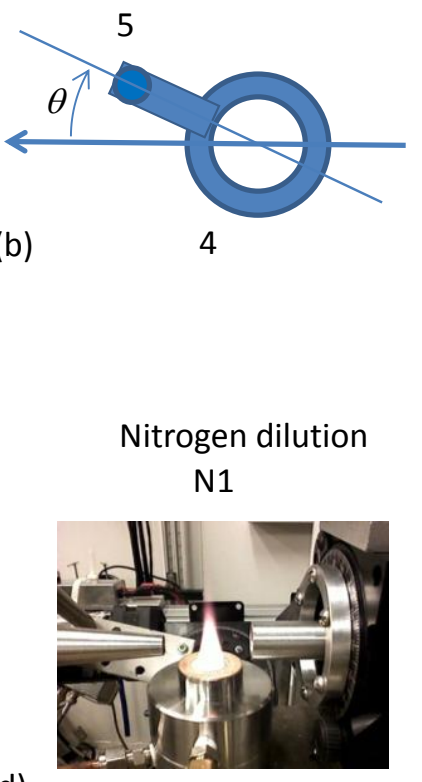

Nitrogen dilution

(d)

Fig.7: The Set-up: (a) View of the set-up against the direction of the X-ray beam; (b) View from above perpendicular to the scattering plane. 1. Burner, 2 gas ducts, 3. flame, 4. rotation stage, 5. detector head; (c) picture of the argon diluted flame $A 1$; (d) picture of the nitrogen diluted flame N1. The direction of X-ray beam is from the right to the left in the photographs (c) and (d) 


\section{Fig.8}

(a)

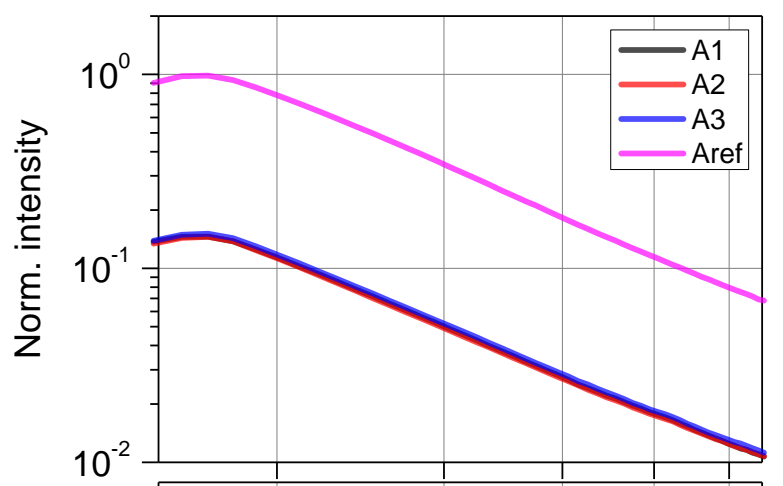

(b)

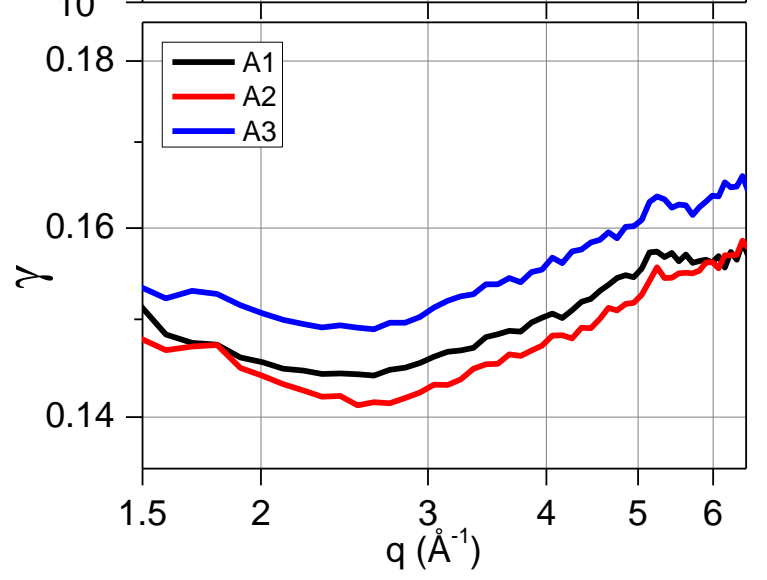

(c)

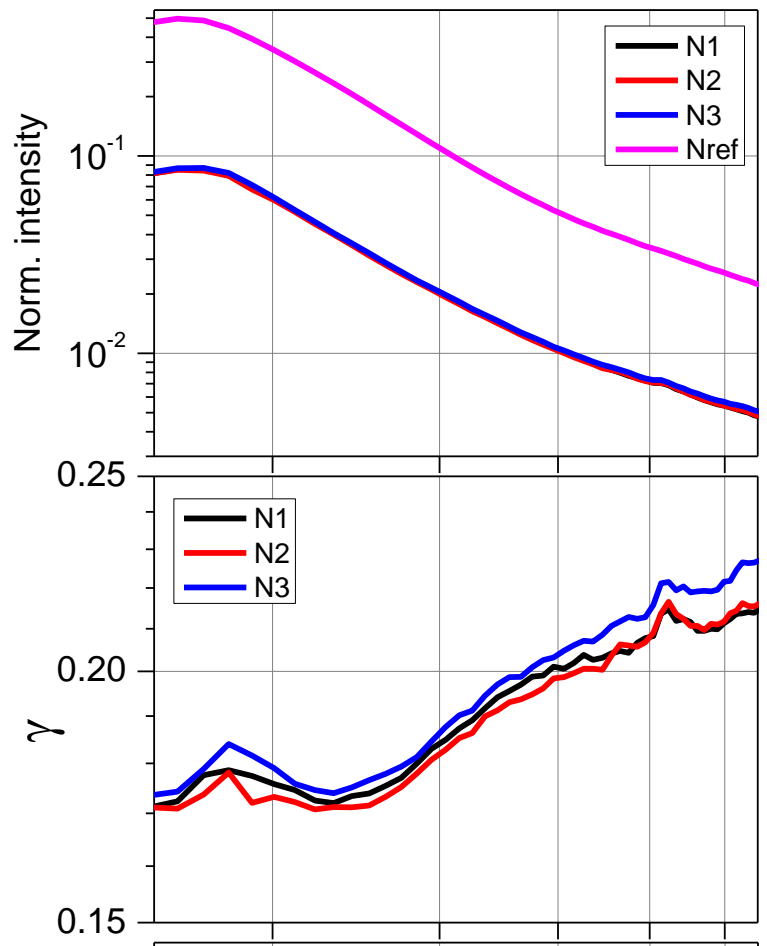

(e)

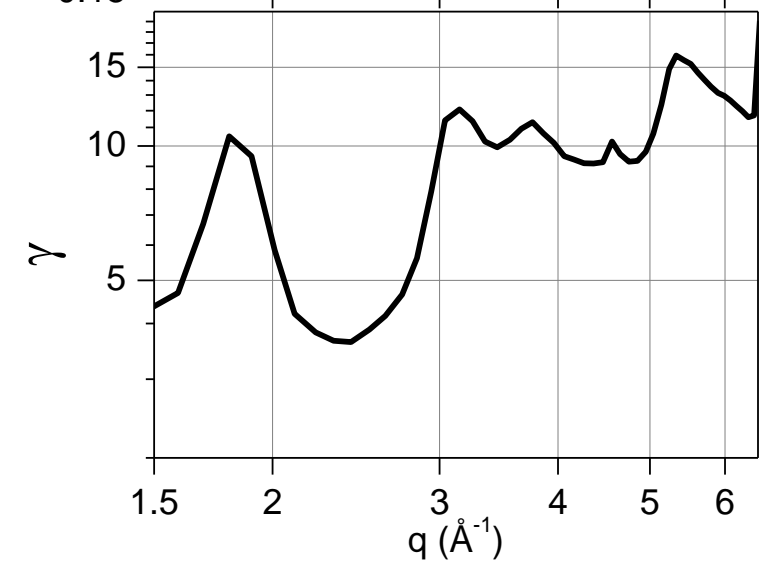

Fig.8: Measured scattering: (a) Scattering intensities for the $A 1-A 3$ flames and the reference condition normalized by the intensity of the X-ray beam; (b) corresponding ratios; (c) scattering intensities for the N1-N3 flames and the reference condition normalized by the intensity of the Xray beam;(d) the corresponding ratio for $\mathrm{Nl}-\mathrm{N} 3$; and (e) the ratio for a soot sample at room temperature (se footnote, Page 17). The relative difference in intensities which are barely 
150916 Time 16:20

discernable in figures (a) and (c) were less than $6 \%$ and $3 \%$ for $q=3 \AA^{-1}$, respectively. However, the differences in the signals are readily seen in the ratio plots (b) and (c). 
Fig.9

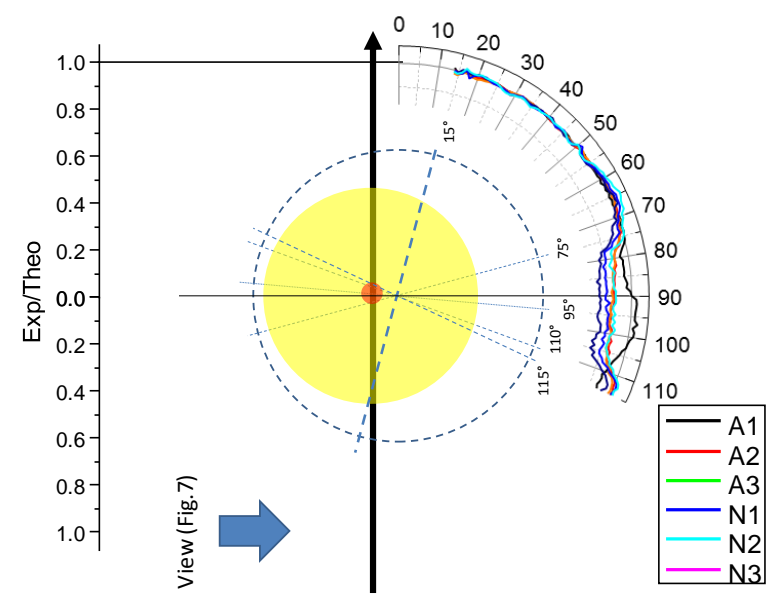

Fig. 9: Summary of comparison between experiments and theory with respect to scattering angle in terms of the ratios between experimental and theoretical scattering intensities. The yellow region and red spot represents the flame and its low density/high temperature region, respectively. The broken-line circle refers to the location of the rotation stage. The blue arrow in the figure indicates the direction of view given by the photos of Fig.7. 
150916 Time 16:20

Fig.10

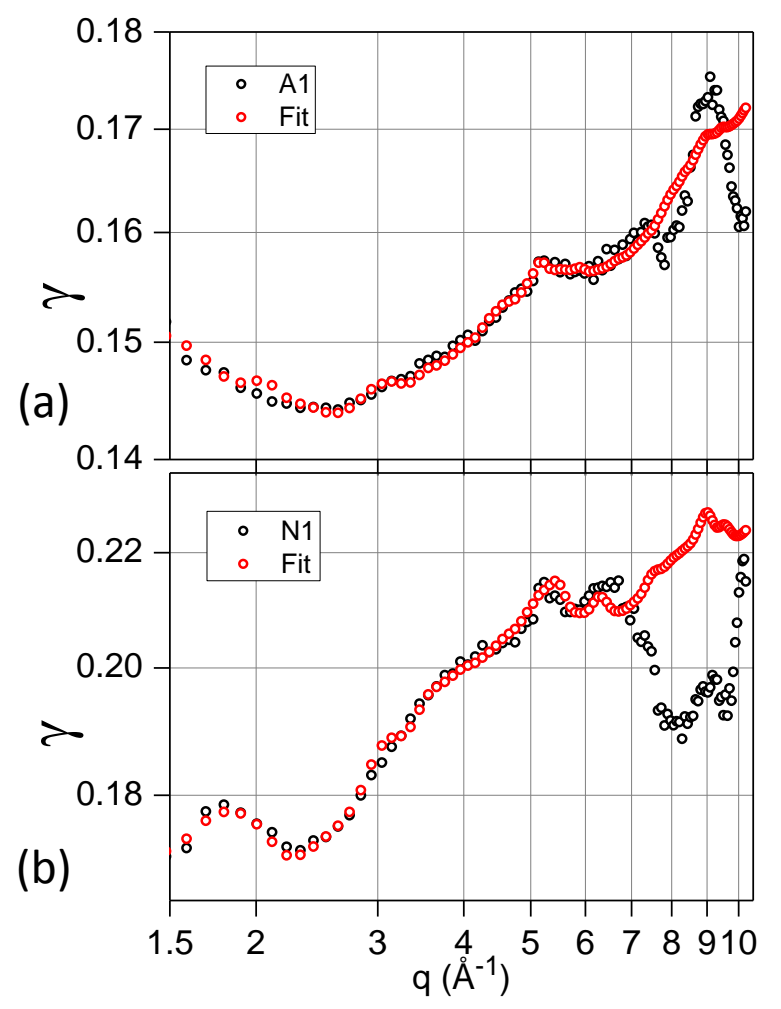

Fig.10: Plots presented in an extended q range. Theoretical data fitted to the experiments for $A 1$ and $N 1$ described in section 4 . The axes of the graphs are in $\log -\log (\mathrm{y}, \mathrm{x})$ scales. 


\section{Fig.11}
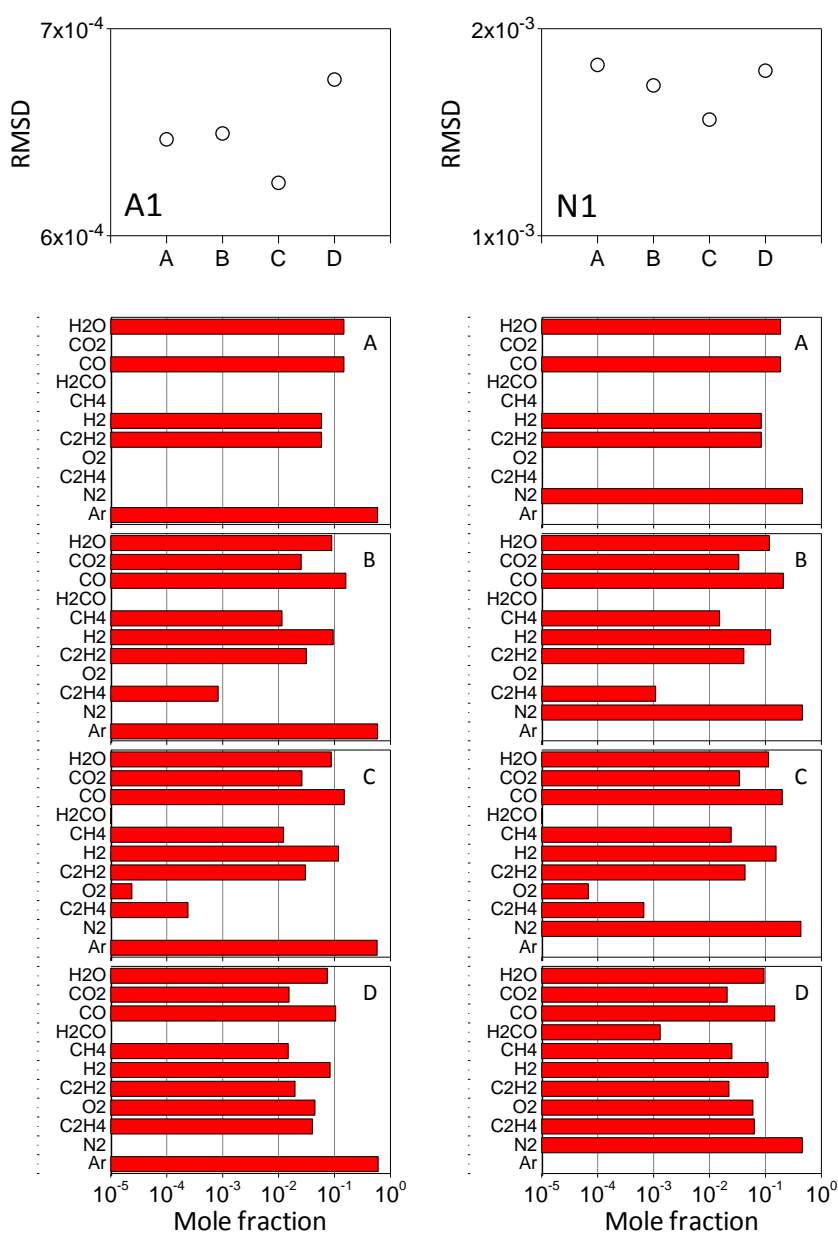

Fig.11: The RMSD between experimental and modeled results of the fits for the argon and nitrogen diluted flames $A l$ and $N 1$. In the lower panels log plots are shown of the respective major species obtained from: (A) RCD, (B) Experimental data from Xu et al., (C) The AramcoMech 1.3 model for the measurement heights, and (D) the AramcoMech 1.3 model for $\mathrm{HAB} 1 \mathrm{~mm}$ as a representation for early chemistry. 


\section{Fig.12}
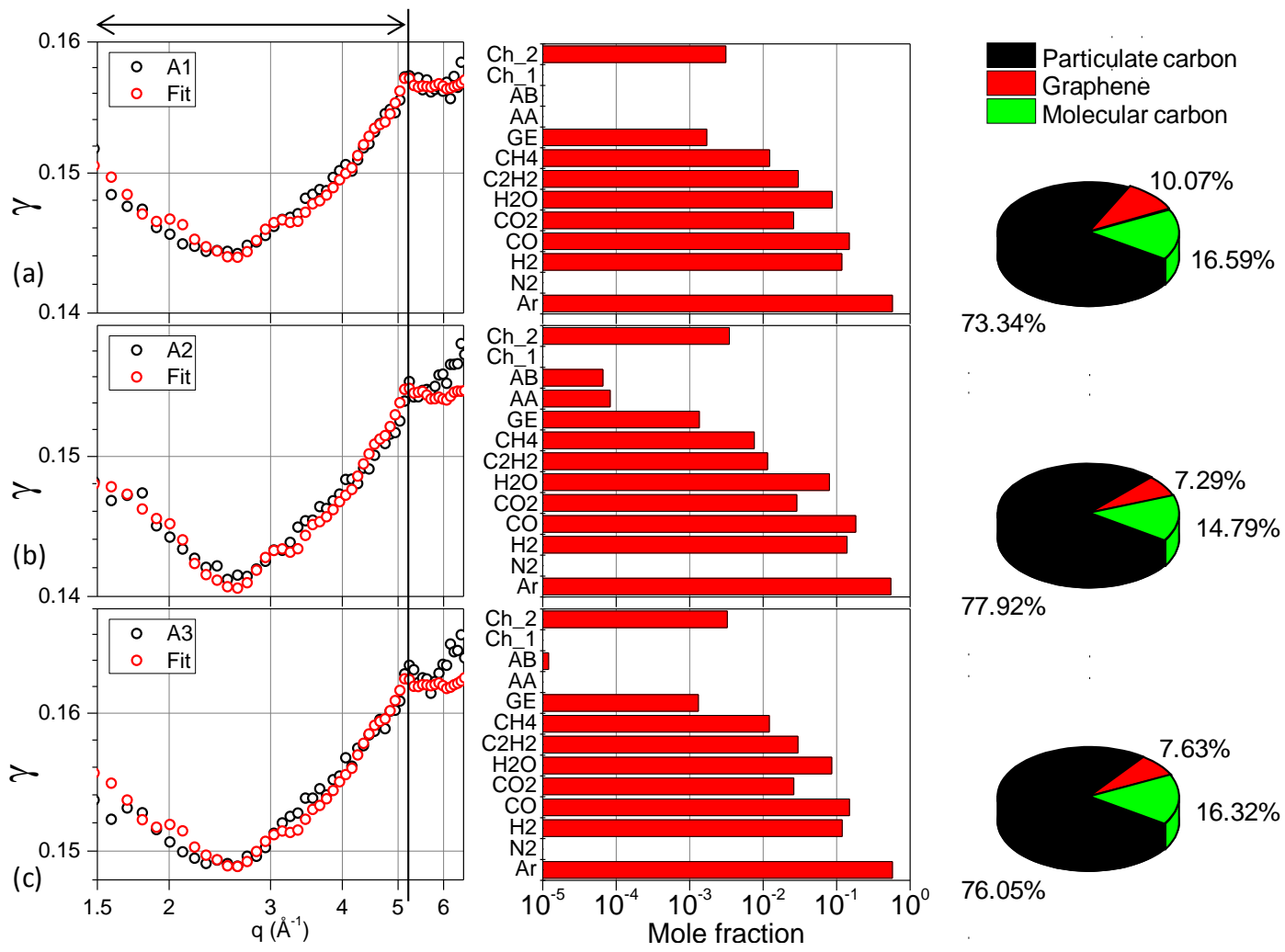

Structured particulate carbon

Amorphous particulate carbon

$3.34 \%$
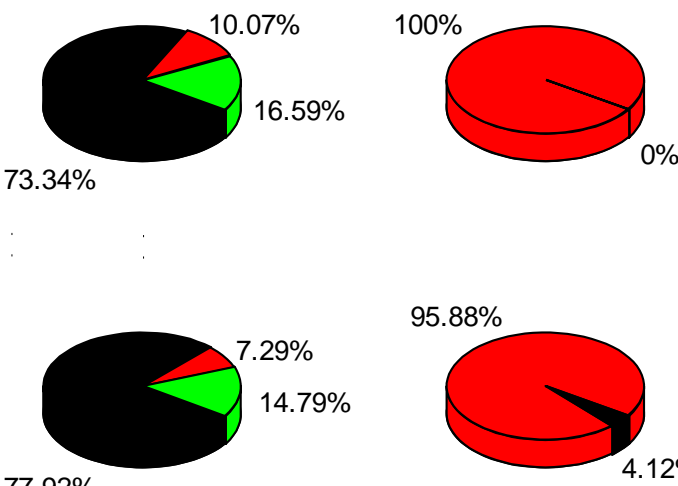

$95.88 \%$
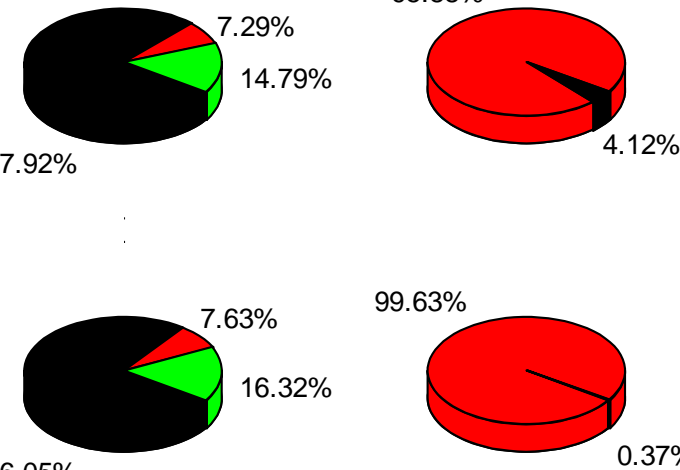

$99.63 \%$

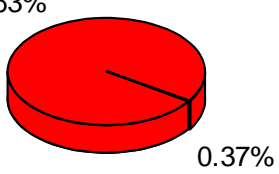

Fig.12: Experimental and calculated data for the argon diluted flames $A 1-A 3: \gamma$, mole fractions (log scale), the phase of the carbon atoms (molecular, precursor/graphene, and particulate), and the level of structure of the particles. The RMSD values are (a) $6.17 \times 10^{-4}$, (b) $7.71 \times 10^{-4}$, and (c) $8.84 \times 10^{-4}$. The temperatures resulting from the fits were (a) $1730 \mathrm{~K}$, (b) $1739 \mathrm{~K}$, and (c) $1675 \mathrm{~K}$. The corresponding temperatures from the chemical simulations were (a) $1764 \mathrm{~K}$, (b) $1794 \mathrm{~K}$, and (c) $1769 \mathrm{~K}$. The fitted $q$-range is given by the double ended arrow in the figure. GE stands for graphene in the species representation. The scattering graphs are in $\log -\log (\mathrm{y}, \mathrm{x})$ scales. 


\section{Fig.13}
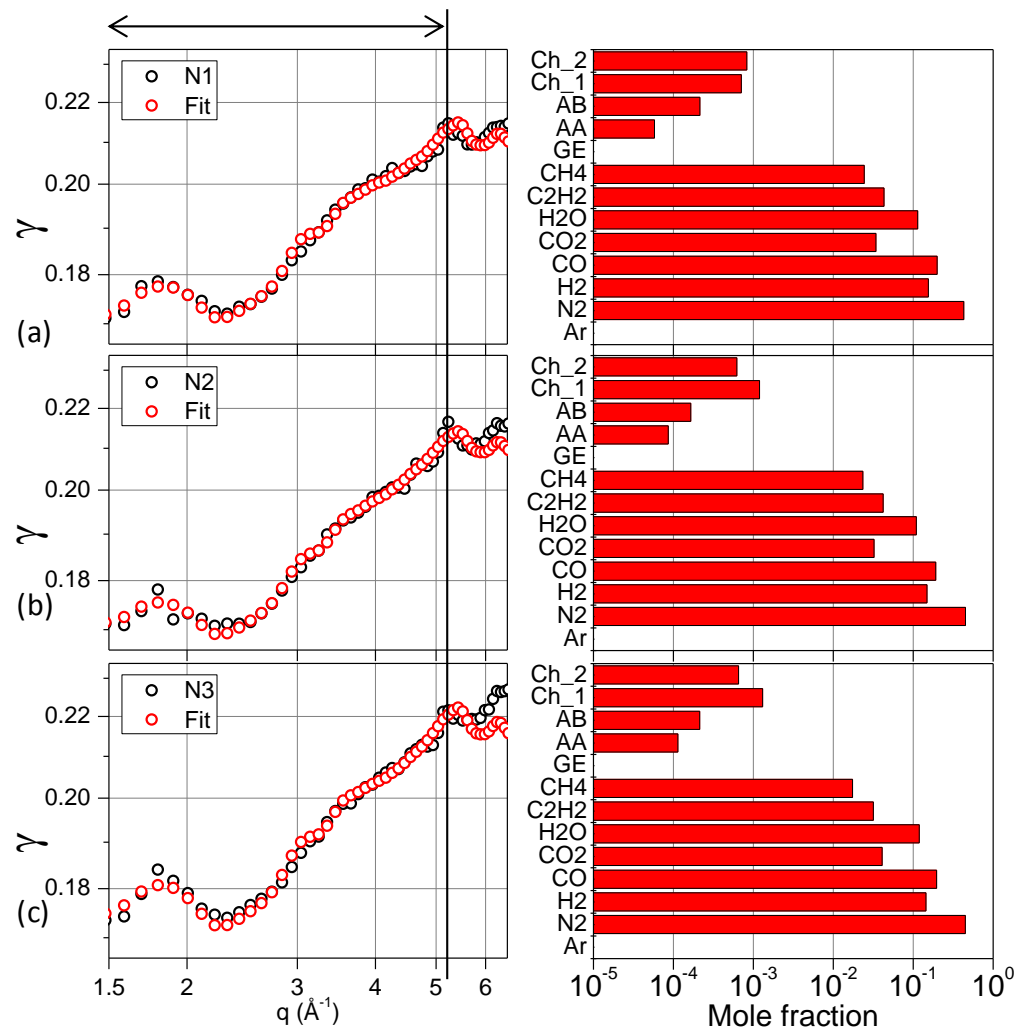
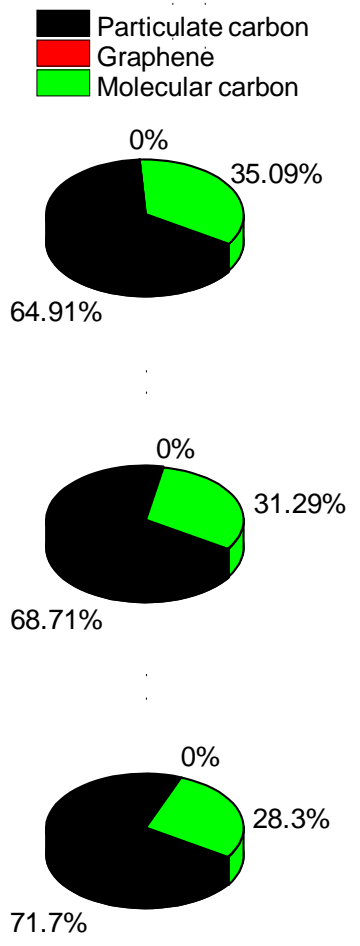

Structured particulate carbon Amorphous particulate carbon
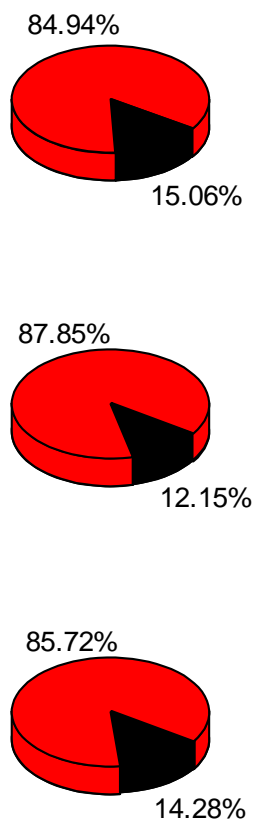

Fig.13: Experimental and calculated data for the nitrogen diluted flames $N 1-N 3: \gamma$, mole fractions (log scale), the phase of the carbon atoms (molecular, precursor/graphene, and particulate), and the level of structure of the particles. The RMSD values are (a) $1.21 \times 10^{-3}$, (b) $1.38 \times 10^{-3}$, and (c) $1.43 \times 10^{-3}$. The temperatures resulting from the fits were (a) $1432 \mathrm{~K}$, (b) $1492 \mathrm{~K}$, and (c) $1501 \mathrm{~K}$. The corresponding temperatures from the chemical simulations were (a) $1644 \mathrm{~K}$, (b) $1657 \mathrm{~K}$, and (c) $1690 \mathrm{~K}$. The fitted $q$-range is given by the double ended arrow in the figure. GE stands for graphene in the species representation. The scattering graphs are in $\log -\log (\mathrm{y}, \mathrm{x})$ scales. 


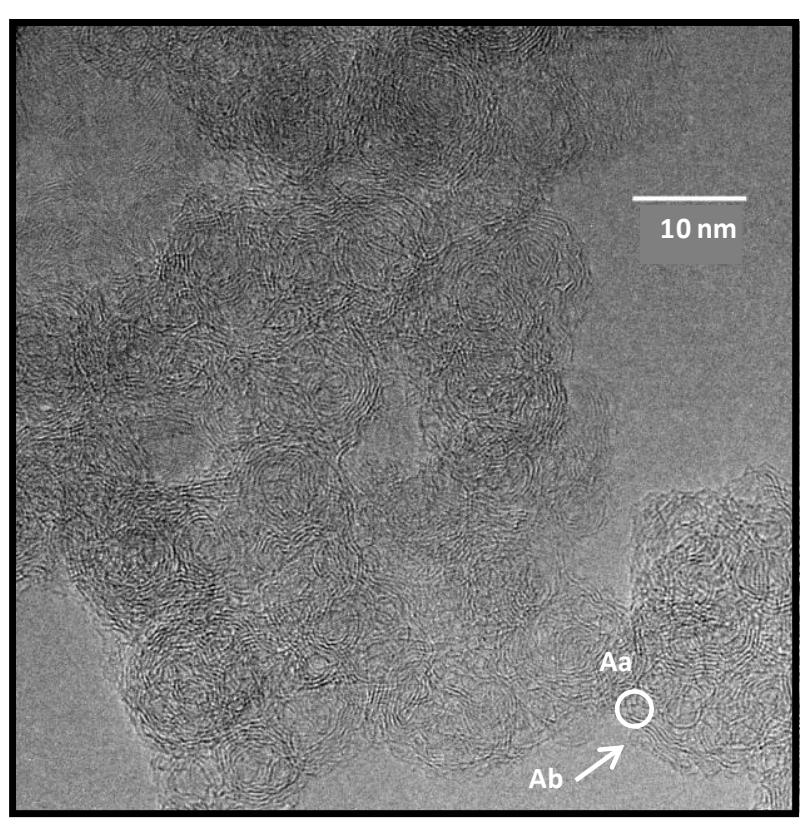

(a)

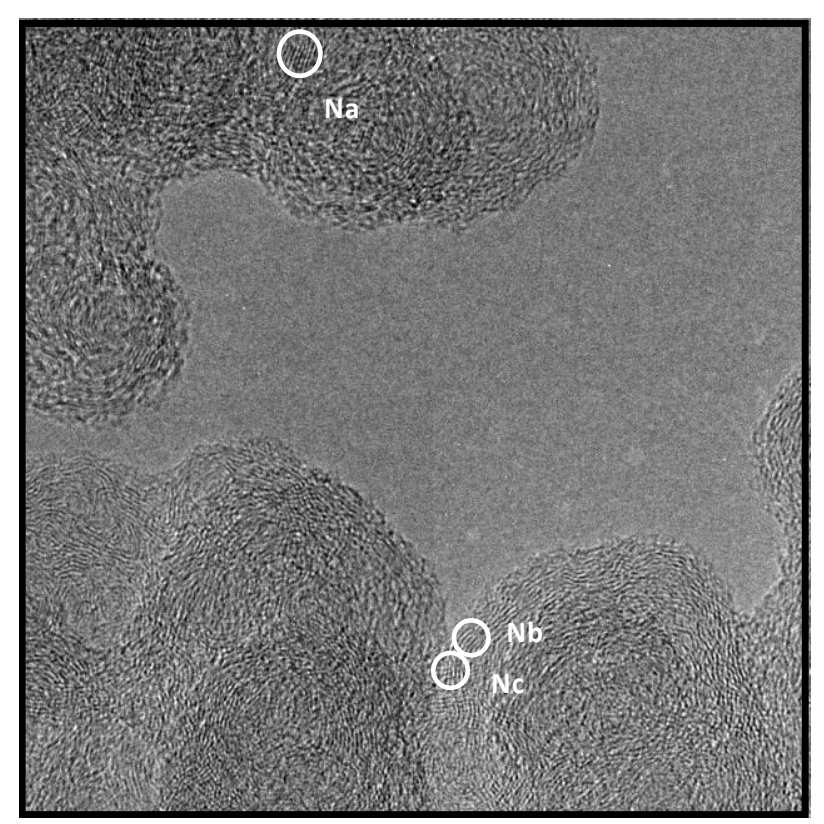

(b)

Fig.14. HRTEM images from Ar- (a) and $\mathrm{N}_{2-}$ (b) diluted flames, $\mathrm{A}^{\prime}$ and $\mathrm{N} 1^{\prime}$. from another burner system with flow conditions corresponding those of $\mathrm{A} 1$ and $\mathrm{N} 1$, but without a $\mathrm{N}_{2}$ shroud. The marked regions Aa and Ab show layered and curved structures in (a), while Na-Nc, show regions of graphitic stacking with straight and curved layers. Blow ups of these regions are shown in Fig. 15. 
Fig. 15

(a)

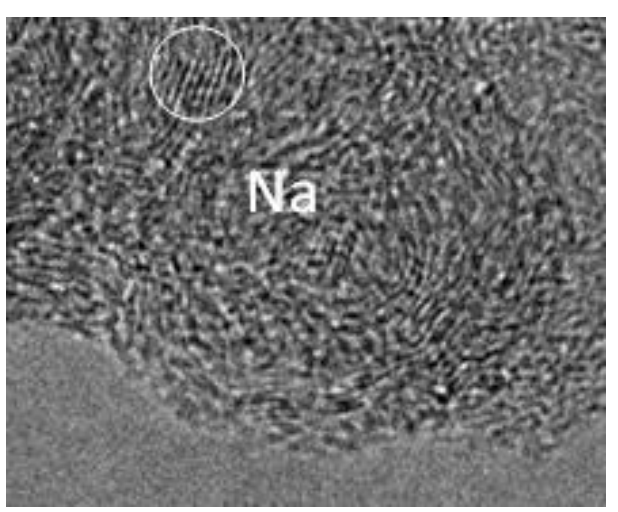

(b)

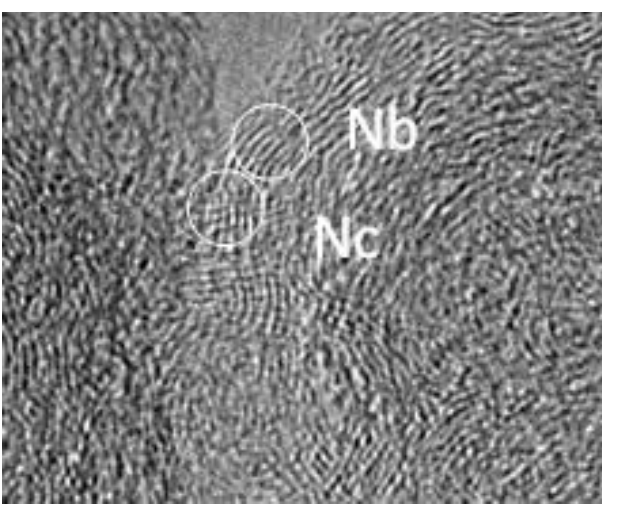

(c)

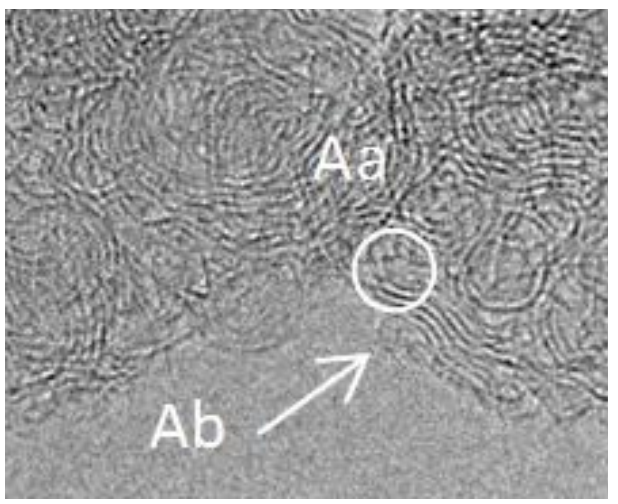

Fig. 15 Blow up of parts of Fig.14. (a) Region $\mathrm{Na}$ (from N1') shows a fringe spacing of $0.34 \mathrm{~nm}$ with almost straight strands; (b) region $\mathrm{Nb}$ yields $0.37 \mathrm{~nm}$, with curved strands, and $\mathrm{Nc} 0.36 \mathrm{~nm}$, with almost straight strands; (c) region Aa (from $A 1$ ') shows a spacing of $0.36 \mathrm{~nm}$ with curved strands while region $\mathrm{Ab}$ shows curved or folded strands with diameters of 1-1.35 nm. 
150916 Time 16:20

$60(65)$ 
Fig. 16

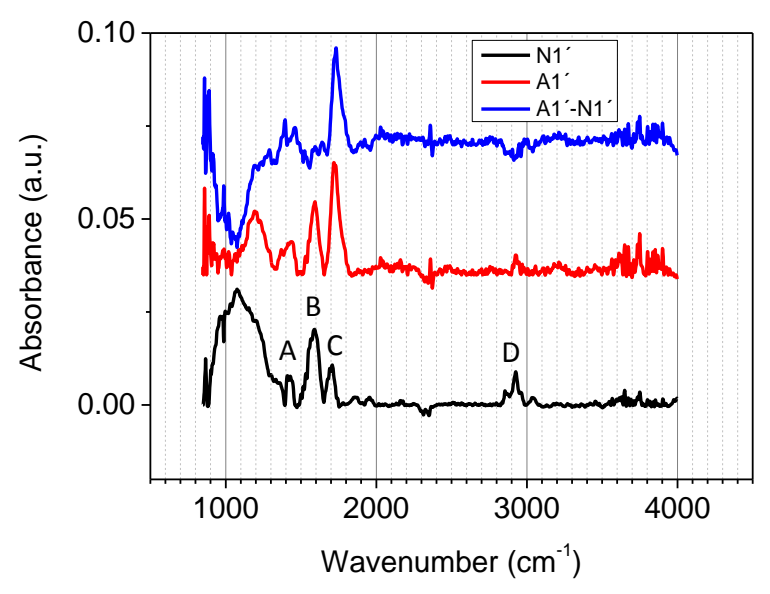

Fig.16 Absorbance as a function of photon energy in the mid-infrared region for materials sampled with copper threads swept through the flames for the $\mathrm{Nl}$ and $\mathrm{Al}$ analogs, $\mathrm{N1} \mathrm{I}^{\prime}$ and $\mathrm{Al} \mathrm{l}^{\prime}$, produced with another but similar burner compared to the one used during the APS measurements campaign. The data is for particle material that showed presence of oxygen. The curve $A l^{\prime}-N l^{\prime}$ is the arithmetic difference between curves $A l^{\prime}$ and $N l^{\prime}$. The letters A-D label the following characteristic stretching vibrations: (A) C-O and C-C; (B) aromatic C-C; (C) carbonyl C-C; and (D) aliphatic C-H. The plots show an offset of 0.035 that has been introduced between the adjacent curves. 
Fig. 17

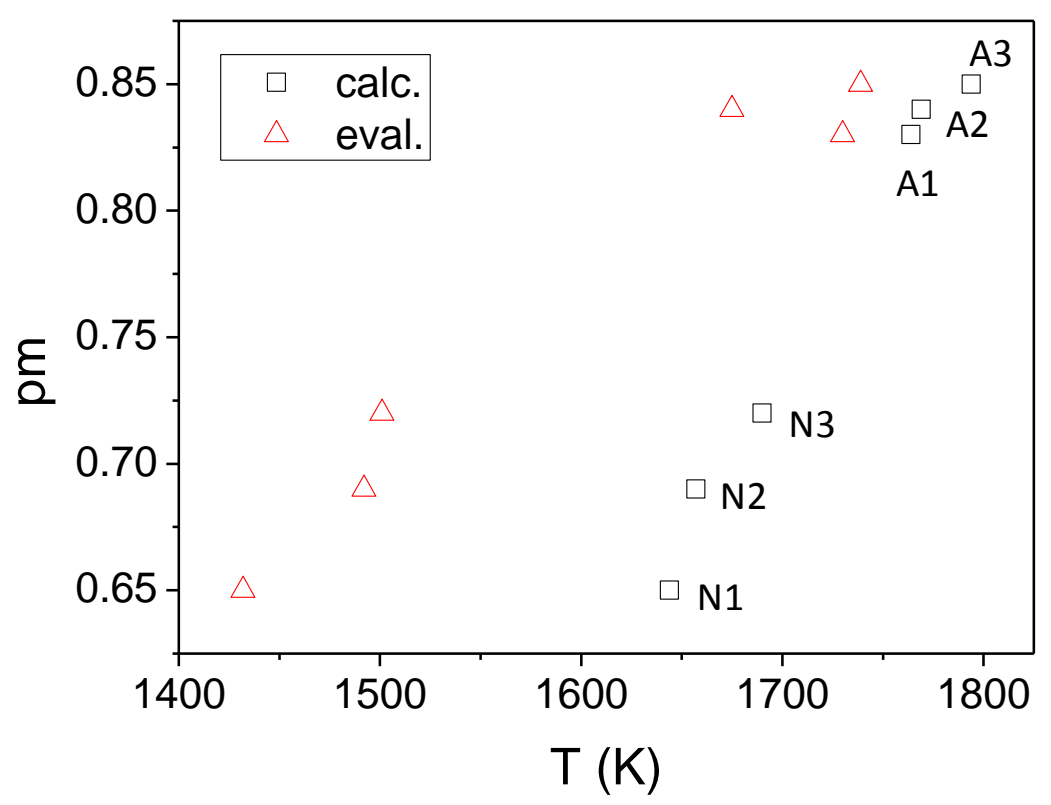

Fig. 17 The relative mass of carbon present in particulate form evaluated from WAXS for the flames A1-A3 and N1-N3 (See Table 3) as a function of flame temperature obtained from calculations with the AramcoMech 1.3 and evaluation from WAXS. 
(a)

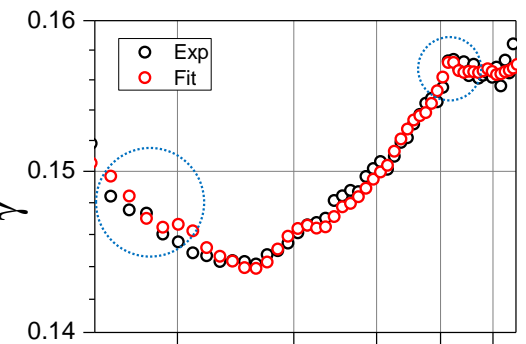

(b)

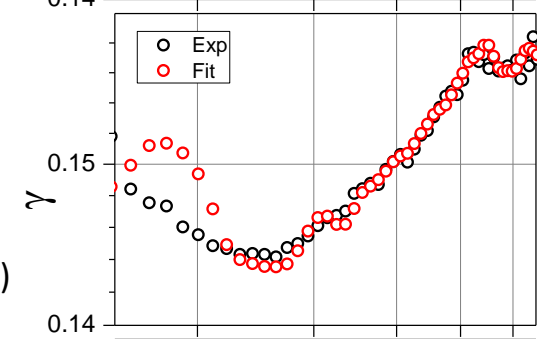

(c)

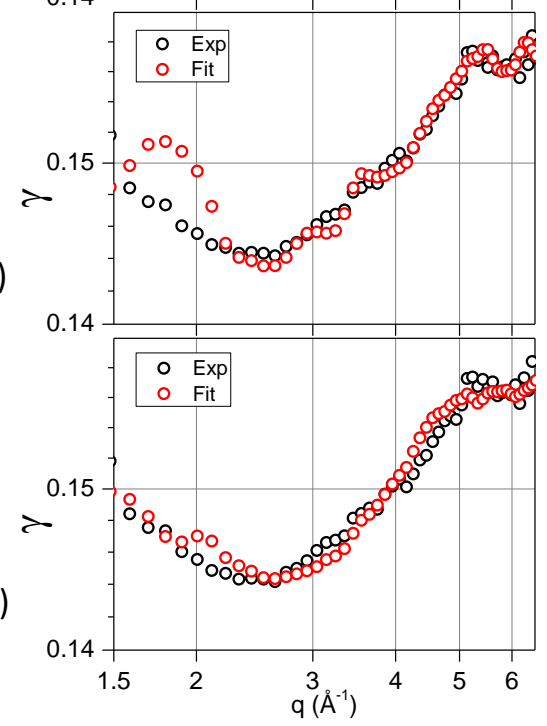

(e)

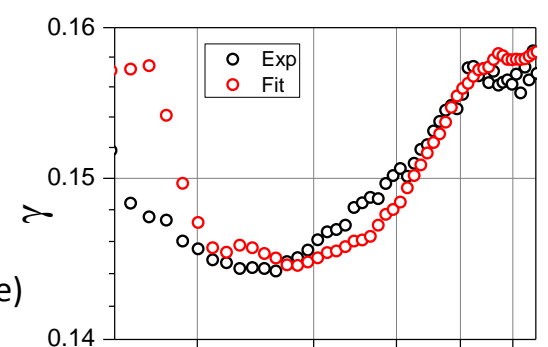

(f)

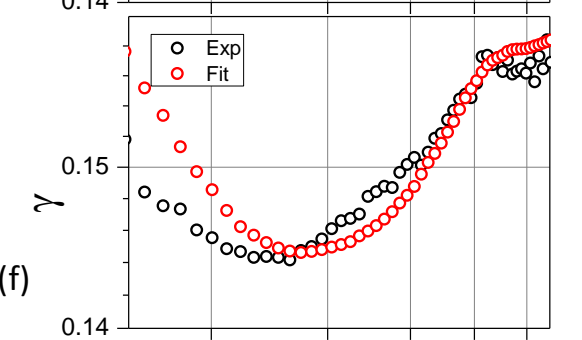

(g)

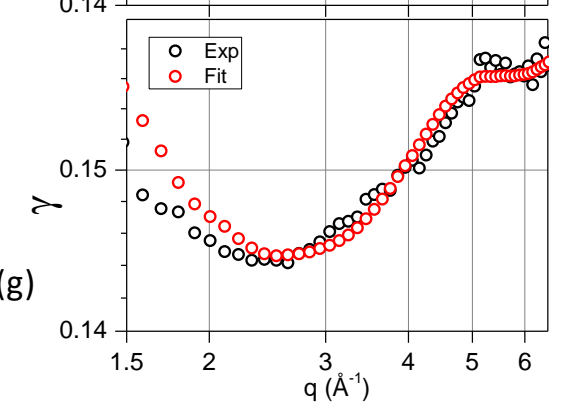

Fig.18 Sensitivity of the fit to the choice of particle parameters for flame A1: (a) shows the best fit of Al using Aramco 1.3 described in section 4.3; (b) the atoms contained in graphene s in (a) were restructured into $\mathrm{AB}$ graphite; (c) as (b) but restructured into AA graphite; (d) All carbon particle atoms were restructured to the amorphous chain type (Ch_2) with a bond distance of 1.54 $\AA$. The graphs' axes are in $\log -\log (\mathrm{y}, \mathrm{x})$ scales. Sensitivity of the fit are also shown for: (e) when all carbon particle atoms were restructured to the amorphous chain type (Ch_1) with a bond distance of $1.42 \AA$; (f) same as (e) but the chain type was chosen as the average for the bond distance $1.42 \AA ;(\mathrm{g})$ also average of chain type but the bond distance is now $1.54 \AA$. The graphs' 
150916 Time 16:20

axes are in $\log -\log (\mathrm{y}, \mathrm{x})$ scales. The broken circles introduced in (a) suggest special regions of detail for the analysis. 
(a)

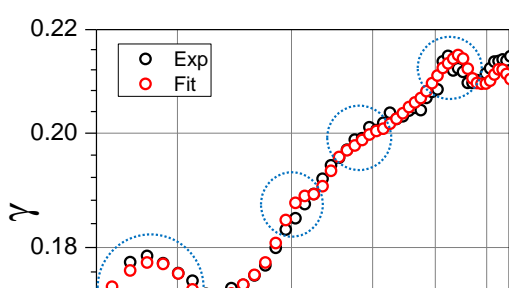

(b)

(c)

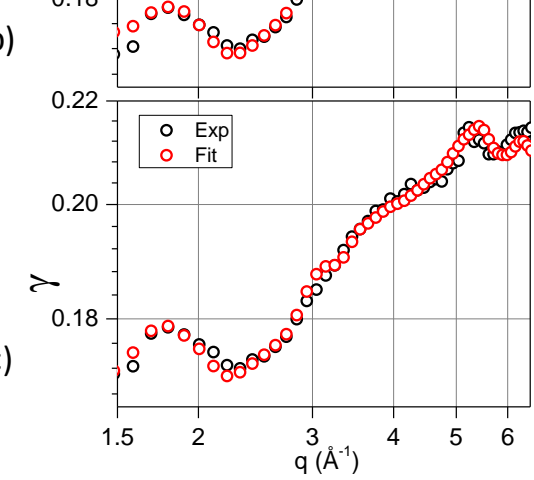

(d)

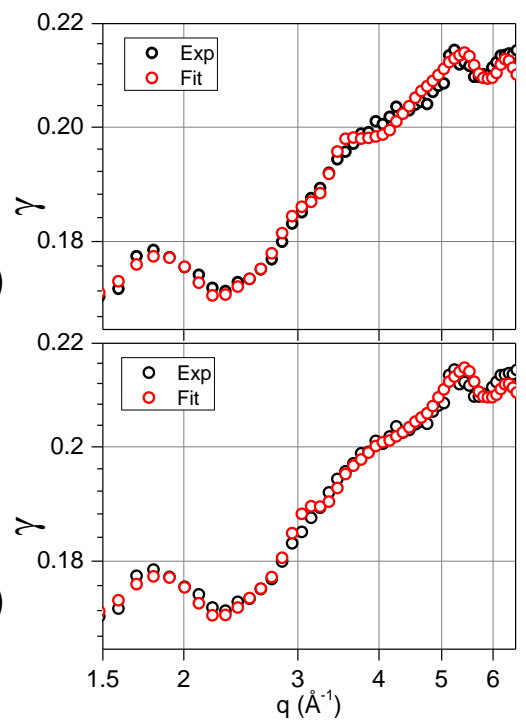

Fig.19 Sensitivity of the fit to the choice of particle parameters for flame $N 1$ : (a) shows the best fit of N1 using Aramco 1.3 described in section 4.3. In this fit the amorphous chains were represented by the average and Ch_2 with 1.42 and $1.54 \AA$ bond distance, respectively; (b) the amorphous chains Ch_2 with a bond distance $1.54 \AA$ was replaced by an average representation; (c) the amorphous chains were represented by Ch_1 and Ch_2 with 1.42 and $1.54 \AA$ bond distance, respectively. The respective RMSD values are: $1.21 \times 10^{-3}, 1.41 \times 10^{-3}$, and $1.29 \times 10^{-3}$. The axes of the graphs are in $\log -\log (\mathrm{y}, \mathrm{x})$ scales. The figure also shows the results for the cases when (d) all the graphite particles were restructured into AA, maintaining the same number of atoms, (e) the same as (d) but restructured to AB. The respective RMSD values are: $1.54 \times 10^{-3}, 1.23 \times 10^{-}$

3. The broken circles introduced in (a) suggest special regions of detail for the analysis. 